\title{
LIBRO RESÚMENES
}

\section{ENCUENTRO DE INVESTIGACIÓN ODONTOLOGÍA UC}

\section{Escuela de Odontología}

Facultad de Medicina

\section{Pontificia Universidad Católica de Chile}

Viernes 7 y sábado 8 de mayo de 2021
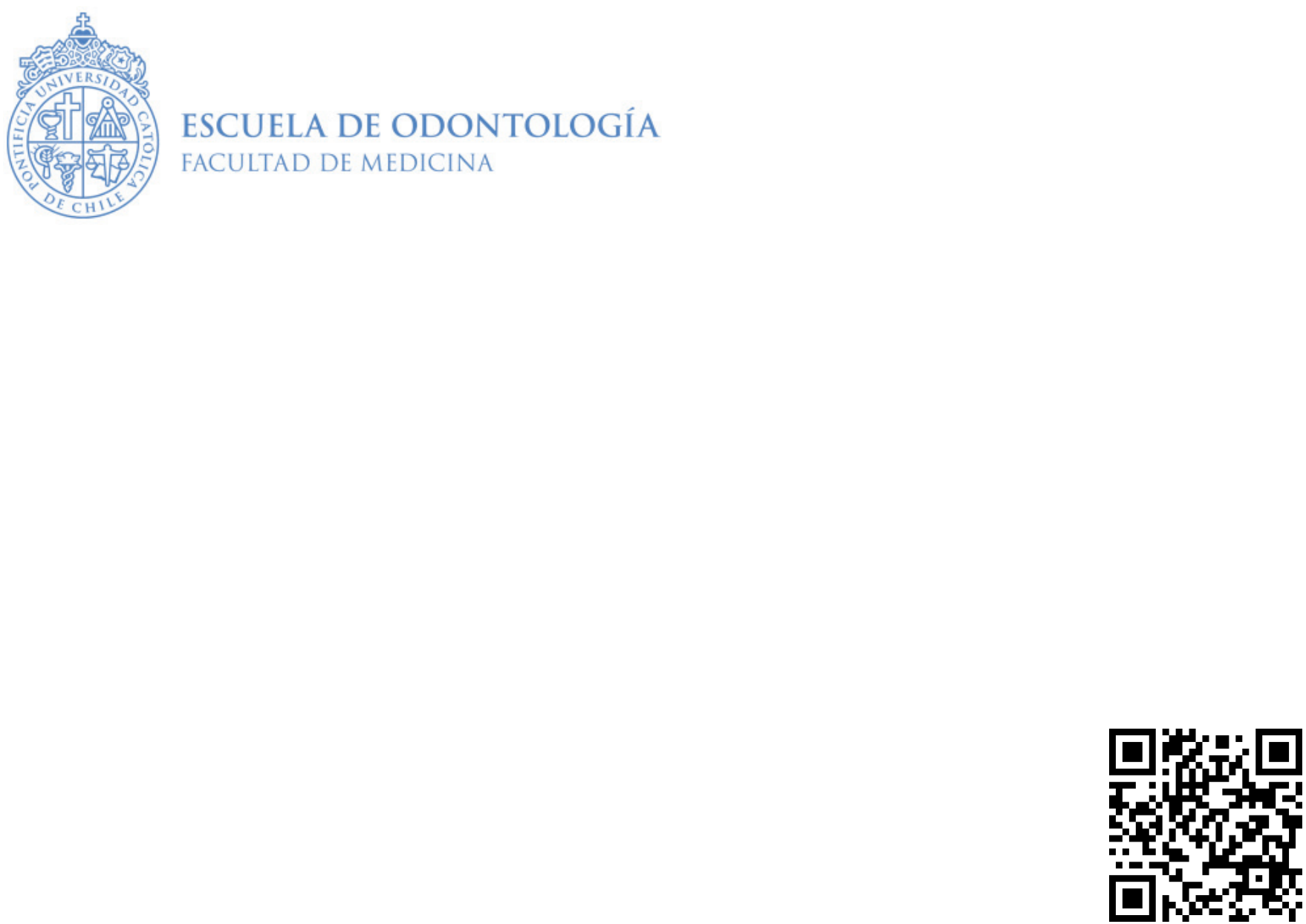
Los días viernes 7 y sábado 8 de mayo se realizó por primera vez en formato virtual a través de la plataforma ZOOM, el IX Encuentro de Investigación de Odontología UC. Este evento fue organizado por la Comisión de Investigación de la Escuela, junto a la Comisión Científica de Estudiantes (CCEO UC). En este encuentro, fueron presentadas 2 conferencias, 5 presentaciones de profesores de la Escuela de Odontología, 5 trabajos de investigación, 9 casos clínicos y 36 revisiones narrativas o sistemáticas en los que participaron estudiantes de pregrado de nuestra Escuela y de varias Facultades de Odontología de nuestro país, de Brasil y Colombia. 


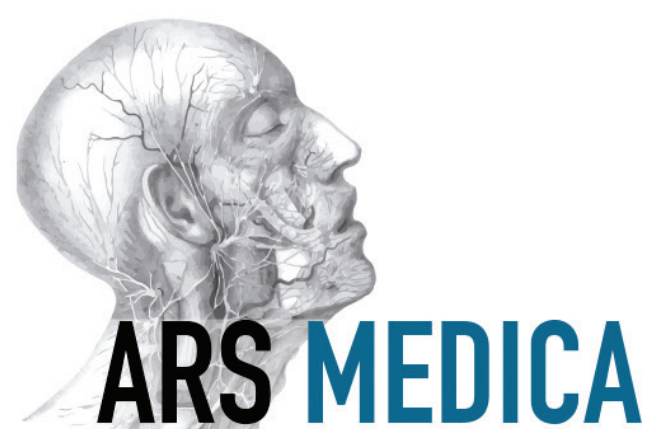
revista de ciencias médicas

\begin{abstract}
COMISIÓN DE INVESTIGACIÓN
ESCUELA DE ODONTOLOGÍA
\end{abstract}

Dra. Constanza Martínez Cardoso

Dra. Bruna Benso

Dr. Sebastián Aguayo

Dr. Humberto González

Dr. Raúl Palacio

\author{
COMISIÓN CIENTÍFICA \\ DE ESTUDIANTES DE ODONTOLOGÍA
}

Francisco Moreno Ferrer

Claudio Carrasco

Nicolás Olivares

Magdalena Yarur 


\section{CONFERENCIA: COVID-19 Y ODONTOLOGÍA: INVESTIGACIÓN EN TIEMPO REAL PARA LA TOMA DE DECISIONES}

\section{DR. DUNIEL ORTUÑO}

Profesor Docente Asistente

Escuela de Odontología, Facultad de Medicina

Pontificia Universidad Católica de Chile

Los betacoronavirus no son agentes infecciosos nuevos, sin embargo, el impacto de la pandemia por COVID-19, teniendo como virus causal el SARS-CoV-2, ha implicado una emergencia sanitaria sin precedentes en el último tiempo. Las medidas poblacionales que se han tomado repercuten en distintos ámbitos, incluyendo los servicios de salud odontológicos. Por otro lado, estudios han mostrado que la cavidad bucal podría jugar un rol importante en la infección y la saliva sería una posible vía de transmisión viral. Una publicación reciente encontró una asociación significativa entre periodontitis y severidad por COVID-19, evidencia que en el contexto de sindemia entre enfermedades crónicas no transmisibles y COVID-19, tendría una plausibilidad biológica dada por ejemplo por la inflamación. Al mismo tiempo se ha señalado que las medidas individuales de higiene bucal podrían disminuir la transmisión en los hogares, lo cual mitiga el riesgo de brotes domiciliarios. El impacto de COVID-19 en Odontología también ha sido reportado en la literatura, entendiendo que la postergación de controles de enfermedades de gran carga de morbilidad como la caries no tratada o la periodontitis podría empeorar la salud bucal de personas adultas, aumentando desenlaces negativos como la pérdida dentaria. En esta última asociación es relevante considerar el rol de los determinantes sociales de la salud como base para un posible aumento de inequidades a mediano y largo plazo, en acceso y condiciones bucales, en Chile y el mundo. La investigación en tiempo real sobre la interacción entre la prevalencia de COVID-19 en la comunidad, los niveles de SARS-CoV-2 en boca y saliva como reservorios, y la cantidad y viabilidad del virus presente en los aerosoles que se producen en procedimientos odontológicos, es fundamental para calcular el riesgo final y retomar las atenciones electivas en un contexto clínico seguro. Los hallazgos científicos respaldan la efectividad de los elementos de protección personal, como los respiradores tipo N95 para procedimientos generadores de aerosoles, recomendación que incluimos en una revisión narrativa, fundamentada en analogía con SARS y MERS. Otras medidas como el uso de test rápido de antígenos, el uso de cuestionarios y triage, y la trazabilidad de las personas que se atienden en los centros odontológicos podrían ser implementadas. Próximamente estará disponible una guía de práctica clínica en Chile, que entregará recomendaciones sobre el uso de elementos de protección personal, ventilación en los espacios clínicos, uso de goma dique y succión de alto volumen, entre otras, durante procedimientos generadores de aerosoles. A largo plazo será necesario evaluar, por ejemplo, en la Encuesta Nacional de Salud 2022-2023, las consecuencias de la suspensión de controles odontológicos por la pandemia en la salud bucal de adultos chilenos y también se necesitan estudios epidemiológicos adicionales que exploren las secuelas de SARS-CoV-2 en el territorio maxilofacial. Finalmente, la investigación será fundamental para generar evidencia que sustente la toma de decisiones en Odontología en futuras pandemias, a partir de lo ocurrido con COVID-19, incluyendo experiencias como la Teleodontología y otras formas de promoción, que permitan seguir entregando salud bucal incluso durante cuarentenas totales.

\section{CONFERENCIA:}

\section{PLASMA CONVALECIENTE ANTI SARS-COV-2 Y COVID-19: DESAFÍOS DEL DESARROLLO DE UN ESTUDIO RANDOMI- ZADO INTERVENCIONAL EN PANDEMIA}

\section{DRA. MARÍA ELVIRA BALLCELS}

Profesor Asociado

Departamento de Enfermedades Infecciosas Escuela de Medicina, Facultad de Medicina Pontificia Universidad Católica de Chile

A mediados de marzo de 2020 contemplábamos inquietos cómo se nos venía encima una nueva pandemia. Los reportes iniciales de COVID-19 mostraban una mortalidad intrahospitalaria mayor al 25\% y desconocíamos completamente alternativas terapéuticas. Nuestro pensamiento diario como médicos y, más aún, perteneciendo a un centro universitario, era ¿cómo podemos contribuir a mitigar esto nosotros? En ese escenario, la amplia experiencia nacional con el uso de plasma convaleciente (PC) para el tratamiento de hantavirus, apareció con fuerza como una opción terapéutica esperanzadora y vimos cómo, a pesar de la casi nula evidencia sobre su eficacia en COVID-19, ya había comenzado a utilizarse ampliamente en otros países como terapia compasiva para pacientes hospitalizados. En esas circunstancias, nos propusimos evaluar de la manera más rigurosa posible la eficacia y seguridad del uso de PC en la progresión de COVID-19. Rápidamente armamos un grupo diverso de investigadores clínicos y básicos (hemato-oncólogos, internistas, infectólogos, intensivistas, pediatras y virólogos, académicos, enfermeras, residentes y alumnos de pregrado), para trabajar a toda máquina en el diseño y logística del estudio. La voluntad común, y la generosidad de todos, hizo posible que acciones muy complejas, como obtener fondos, conformar equipos entrenados en estudios clínicos, obtener aprobaciones éticas, autorizaciones, logística de implementación y campaña de difusión interna y externa, pudieran desarrollarse 
en tiempo record. El estudio consistió en un ensayo clínico aleatorizado, abierto, que incluyó a pacientes hospitalizados dentro en la primera semana de aparición de síntomas de COVID-19, que tenían factores de riesgo para la progresión de la enfermedad. La intervención consistió en la administración de PC inmediata versus no administración de PC, a menos que se desarrollaran criterios de deterioro pre especificados. No demostramos beneficios en el desenlace primario respecto a riesgo de muerte, ventilación mecánica o estadía hospitalaria prolongada (32,1\% vs 33,3\%, p> 0,999 ) entre ambos grupos ${ }^{1}$. Si bien fue un estudio pequeño y los resultados no permitieron confirmar ninguna eficacia del PC, este igualmente contribuyó al pool de evidencia que, en diversos países $^{2}$, meses después, estableció que el PC no es de beneficio en pacientes hospitalizados por COVID-19, en plena concordancia con nuestros hallazgos. Además, en su desarrollo, este proceso generó mucho aprendizaje para todos los participantes. Nuestros criterios de inclusión estrictos y los desafíos del enrolamiento 24/7 en una enfermedad grave, en contexto de aislamiento respiratorio y mucha angustia en las familias y pacientes, fueron solo parte de los grandes desafíos del proceso. En definitiva, una conclusión muy importante de este trabajo fue saber que tenemos la capacidad de hacer estudios clínicos propios de impacto global, por lo que me atrevo a decir que es un deber de universidades grandes, como la nuestra, invertir en ellos y hacerlos. 
Volumen 46 suplemento 1

\section{Presentaciones profesores de la Escuela de Odontología UC}




\section{EFECTOS BIOLÓGICOS DE CONCENTRADOS PLAQUETARIOS EN LA CICATRIZACIÓN TISULAR}

\section{DRA. CONSTANZA MARTÍNEZ CARDOZO}

Profesor Asociado

Escuela de Odontología, Facultad de Medicina

Pontificia Universidad Católica de Chile

El uso de concentrados plaquetarios humanos como una herramienta autóloga para la liberación de factores de crecimiento y proteínas, ha generado un importante interés para promover la reparación y regeneración tisular en diferentes situaciones clínicas. El uso de estos derivados plasmáticos se basa en algunos de los eventos que ocurren durante el proceso de reparación tisular fisiológica, que incluye el ro indispensable de las plaquetas en la formación del coágulo de fibrina y la liberación de biomoléculas y factores de crecimiento que gatillan un efecto en la proliferación, migración y diferenciación de las células que participan en la cicatrización tisular. Así mismo, se ha sugerido que liberan factores que estimulan la angiogénesis, otro proceso indispensable para el éxito de este proceso. En esta presentación resumimos los principales hallazgos de nuestro grupo de investigación, relacionados con el efecto de los concentrados plaquetarios, incluyendo el Plasma Rico en Plaquetas (PRP), Plasma Pobre en plaquetas (PPP) y la Fibrina Rica en Plaquetas y Leucocitos (L-PRF) en diferentes actividades biológicas que son indispensables para que se lleve a cabo el proceso de cicatrización tisular. Para ello hemos usado un modelo de cultivos primarios de células del ligamento periodontal humano adulto. En este modelo, demostramos que tanto PPP como PRP estimulan la proliferación celular de los subtipos de células mesenquimáticas presentes en el ligamento periodontal identificadas por los marcadores de superficie CD105, CD146, CD73 y CD90. Igualmente hemos evidenciado que la incubación de estas células con PPP o PRP a diferentes concentraciones estimula la diferenciación óseo/ cemento. Finalmente estamos estudiando los efectos de medios condicionados y exudados obtenidos a partir de membranas y coágulos de L-PRF derivado de individuos fumadores y no fumadores.

Estos hallazgos pueden tener implicaciones para futuras terapias que tengan como objetivo estimular la regeneración periodontal utilizando factores de crecimiento autólogos.

\section{MODELOS IN SILLICO COMO HERRAMIENTA DE PREDICCIÓN DEL COMPORTAMIENTO DE FÁRMACOS}

\section{DRA. BRUNA BENSO}

Profesor Asistente, Escuela de Odontología,

Facultad de Medicina, Pontificia Universidad Católica de Chile

La lidocaína es una sal anestésica anfifllica utilizada en el control del dolor crónico o agudo y que junto a los tienen toxicidad proporcional a la potencia farmacológica. La principal aplicación clínica es el alivio del dolor interrumpiendo la conducción nerviosa bloqueando a los movimientos de iones de sodio en la célula nerviosa, evitando la propagación del estimulo nervioso. Por otro lado, se sabe que la hidrofobicidad de los anestésicos locales es directamente proporcional a la duración de la anestesia. Como las características deseables para una molécula anestésica incluyen, además de extensa duración de la acción y selectividad para el bloqueo sensorial en bloqueo motor, la reducción de la toxicidad local y sistémico, una alternativa, que actualmente ha demostrado ser capaz para promover estos efectos deseables, es la liberación modificada de estos fármacos, mediante la formación de complejos de inclusión con ciclodextrinas. Además de la estabilización, la modificación de las propiedades farmacocinéticas y biofarmacéuticas de los fármacos son los efectos mas importantes de la complejización con ciclodextrina. Estos efectos se observan en la solubilidad y en la liberación lenta del fármaco complejizado siendo de interés por la industria farmacológica. Nuestros resultados muestran que la caracterización optima de lidocaína na complejizaada 2-hidroxipropil-beta-ciclodextrina es 1:1. Sin embargo, para su aplicación clínica es necesario conocer el perfil de liberación y difusión en los tejidos de interés utilizando modelos dinámicos. El presente trabajo busca caracterizar in sillico el perfil de liberación del sistema de 2-hidroxipropil-b-ciclodextrina usando modelos matemáticos (ecuaciónprincipal de difusión de Fick) para drug delivery aplicado a la $\mathrm{v}$ a de administración oral. El resultado principal esperado es determinar las diferencias en la cinética de la liberación de la sal anestésica tradicional de uso clínico y compararla a la formulación modificada para liberación lenta con incorporación de beta-ciclodextrina y de este modo poder avanzar en modelos clínicos de validación de nuevos fármacos. 


\section{ANÁLISIS DE COSTO-EFECTIVIDAD EN ODONTOLOGÍA \\ DR. RAÚL PALACIO}

Profesor Asistente adjunto, Escuela de Odontología,

Facultad de Medicina, Pontificia Universidad Católica de Chile

Constantemente los tomadores de decisiones se ven enfrentados a elegir una intervención en salud por sobre otra. Para tomar una decisión se deben considerar puntos importantes, uno de ellos es que las intervenciones sean clínicamente seguras. También se debe tener en cuenta que las intervenciones tengan un efecto comprobado y respaldado por la evidencia científica, en otras palabras, que sean clínicamente eficaces. Un punto no menor es el costo de las intervenciones, más aún, cuando estas intervenciones serán ejecutadas en el subsistema público pagadas con fondos públicos, es decir, fondos aportados por los contribuyentes.

Una forma de contrastar las intervenciones en salud es mediante el uso de evaluaciones económicas como, por ejemplo, los análisis de costo-efectividad (ACE). Estos análisis comparan los costos y los efectos (consecuencias) de dos o más intervenciones en un área muy específica y con presupuestos limitados. Sin importar lo anterior, este tipo de análisis son los más utilizados en odontología. A nivel nacional, se han ejecutado ACEs donde el análisis de intervenciones de carácter preventivo domina el escenario. A modo de ejemplo, en Odontología UC estamos desarrollando estudios cuyos resultados (a la espera de publicarlos) demuestran que la utilización de barniz de flúor en la población preescolar es costo-efectiva al aumentar la cantidad de niños libre de caries (ceod=0), no obstante, dicho efecto es muy reducido y está asociado a costos significativos; considerando esto, hemos propuesto intervenciones más costo-efectivas.

Estos tipos de estudios muestran el importante rol que pueden jugar los ACEs en odontología y el uso de esta metodología como metodología de evaluación ex-ante para programas de salud pública, por ejemplo. Sin embargo, a pesar del aumento de ACEs en odontología durante los últimos años, se requieren más estudios económicos en odontología.

\section{NANO-MECANOBIOLOGÍA ORAL: EXPLORANDO INTERAC- CIONES ENTRE COLONIZADORES BACTERIANOS Y SUPERFI- CIES A NANOESCALA}

\section{DR. SEBASTIÁN AGUAYO}

Profesor Asistente

Escuela de Odontología, Facultad de Medicina, Instituto de Ingeniería Biológica y Médica

Facultades de Ingeniería, Medicina y Ciencias Biológicas, Pontificia Universidad Católica de Chile.

Actualmente existe un profundo interés por comprender los mecanismos detrás de la colonización inicial de superficies y su rol en el desarrollo de enfermedades mediadas por biopelículas. Las biopelículas son comunidades bacterianas adheridas a superficies, cuya desregulación ecológica se encuentra asociada a prevalentes enfermedades orales tales como tales como caries dental y enfermedad periodontal. Por ello, nuevos avances en la disciplina de mecanobiología buscan estudiar cómo las propiedades mecánicas de bacterias y biopelículas, junto a fuerzas físicas del entorno, influencian su comportamiento biológico en el contexto de enfermedad, para así potencialmente desarrollar nuevos enfoques preventivos y terapéuticos contra caries dental y enfermedad periodontal. Entre ellas, el uso de microscopía de fuerza atómica (AFM) permite caracterizar las interacciones entre colonizadores bacterianos iniciales, tales como Streptococcus mutans y Streptococcus sanguinis, y superficies de interés biológico y terapéutico, a escala nanométrica. Durante los últimos años, estas nuevas técnicas avanzadas de microscopía han potenciado el estudio de mecanobiología bacteriana en el contexto de caries dental, enfermedad periodontal, y peri-implantitis, utilizando bacterias vivas en condiciones fisiológicas, y permitiendo el análisis de interacciones entre adhesinas de superficie y sustratos a nivel subcelular y molecular. Más aún, el uso de AFM ha permitido el análisis de las propiedades mecánicas de biopelículas y su matriz extracelular con precisión nanométrica, demostrando cambios a nivel de adhesividad y elasticidad asociados a cambios ambientales, tales como concentración de azúcar. En esta presentación, se hará una introducción al tópico de mecanobiología asociada al estudio nanométrico de bacterias y biopelículas (nano-mecanobiología), y cómo en los últimos años hemos utilizado estas técnicas para el estudio de importantes interacciones entre microorganismos y sustratos en el contexto de enfermedades orales y biopelículas asociadas a colonización de implantes, candidiasis sub-protésica, y caries dental, entre otros. 


\section{ENFERMEDAD PERIODONTAL Y SU RELACIÓN CON CONDICIONES SISTÉMICAS}

\section{DRA. MAITE SOUYET}

Profesor Asistente, Escuela de Odontología,

Facultad de Medicina, Pontificia Universidad Católica de Chile

Las enfermedades periodontales son un grupo de alteraciones que afectan los tejidos que soportan los dientes. La inflamación del tejido blando, o encía, se llama gingivitis y está provocada principalmente por acumulo de biofilm bacteriano (Chapple et al; 2018). La periodontitis es la destrucción irreversible del tejido de soporte, provocando perdida de inserción, reabsorción ósea $y$, en su estado más grave, la pérdida de la pieza dentaria (Tonetti et al; 2015).

La periodontitis es desencadenada por una disbiosis bacteriana y modificada por diversos factores, dentro de los cuales la diabetes mal controlada y el tabaquismo son factores sistémicos de riesgo que modifican la aparición y avance de la periodontitis (Kinane et al, 2015; Albandar et al, 2018). En un sentido inverso se ha observado que los productos inflamatorios periodontales $y$ algunas bacterias -con sus productos- podrían viajar por el torrente sanguíneo afectando tejidos y consecuentes desbalances sistémicos a distancia (Offenbacher et al; 1989). Las condiciones sistémicas, afectadas por la periodontitis, más estudiadas actualmente son los eventos cardiovasculares, eventos adversos en embarazo y mal control metabólico en pacientes diabéticos (Monsarrat et al, 2014).
Nuestro equipo, junto a diferentes departamentos de la Facultad de medicina de la Pontificia Universidad Católica de Chile, está estudiando la eventual relación entre periodontitis con lupus eritematoso sistémico, insuficiencia renal crónica y cirrosis hepática no alcohólica (y sus complicaciones). La relación de periodontitis con estas diferentes condiciones ha sido estudiada anteriormente, pero se necesita mayor información para establecer una relación directa entre la periodontitis y estas condiciones.

\section{INVESTIGACIÓN CLÍNICO-BÁSICA EN PERIODONCIA}

\section{DR. PATRICIO SMITH F.}

Profesor Asociado, Escuela de Odontología,

Facultad de Medicina, Pontificia Universidad Católica de Chile

Las enfermedades periodontales aumentan en su prevalencia y severidad de manera muy significativa producto del envejecimiento. Sin embargo, los mecanismos biológicos que permiten explicar la contribución del envejecimiento al deterioro de estos tejidos es, hasta el momento, poco conocido. La reparación del tejido conectivo depende críticamente de la diferenciación de miofibroblastos, células responsables de la síntesis y organización de fibras de colágeno. En estudios previos hemos detectado que la diferenciación de estas células está severamente alterada en fibroblastos provenientes de pacientes mayores. Por otro lado, fibroblastos senescentes desarrollan alteraciones en la capacidad de remodelación de tejidos conectivos y colágeno en especial. En esta conferencia se discutieron estos resultados y se propusieron líneas de trabajo en esta área disciplinar. 


\section{Trabajos de Investigación}




\section{Pérdida de dientes y percepción de salud oral: ENS 2016-2017}

Claudio Carrasco Mococain ${ }^{1}$, Francisco Moreno Ferrer ${ }^{1}$, Beatriz Mellado Torres ${ }^{1}$, Juan Vargas Buratovic ${ }^{1}$, Duniel Ortuño Borroto ${ }^{1}$

'Escuela de Odontología, Facultad de Medicina, Pontificia Universidad Católica de Chile.

Objetivo: Evaluar la percepción de calidad de vida relacionada con salud oral (OHRQoL) en chilenos sobre los 15 años que participaron en la Encuesta Nacional de Salud 2016-2017 (ENS 2016-2017).

Métodos: Este estudio incluyó a 5473 individuos, a los que se les realizó un examen intraoral. Para medir el OHRQoL se realizó una pregunta general: “Cómo calificarías tu salud oral?", a lo que se podía responder: "Excelente", “Buena”, "Neutral", "Pobre” y "Muy Pobre". El cálculo de la media y proporciones se hicieron con sus respectivas desviaciones estándar (sd) e intervalos de confianza (IC) del 95\% usando muestras complejas. Se realizaron regresiones lineales para el número de dientes y logísticas para la pérdida de piezas anteriores, obteniendo Odds Ratios (OR) con su IC de 95\%. Se ajustó por edad, sexo, área geográfica y nivel educacional.

Resultados: Para los participantes que calificaron de "Excelente" su salud oral la media de dientes fue de 24.32 (sd 0.62), mientras que para los que la consideraban "Pobre" $y$ "Muy Pobre" fue de 15.13 (sd 0.34 ) y 12.88 (sd 0.92) dientes respectivamente. Con respecto a la pérdida de dientes anteriores, tanto como para maxilar y mandíbula se reportaron diferencias significativas ( $p$-value<0.001). Además, se observó que los sujetos con percepción de salud oral "Pobre" obtuvieron un OR de pérdida de dientes anterosuperiores de 2.33 (CI 95\% 1.05-5.17), mientras que los con "Muy Pobre" tuvieron uno de 3.27 (Cl 95\% 0.97-11.06). Con respecto a la pérdida de dientes anteroinferiores se observó una gradiente similar pero menor que a la obtenida para dientes anterosuperiores.

Conclusiones: Un menor número de dientes remanentes se asoció con una peor OHRQoL. En cuanto a las piezas anteriores se vio que las personas que responden "Pobre" o"Muy Pobre" tenían una chance mayor de presentar pérdida de piezas anterosuperiores.

\section{Influencia del área de aplicación en la terapia blanqueadora: alteración cromática y sensibilidad postoperatoria}

Lara Maria Bueno Esteves ${ }^{1}$, Paulo Henrique dos Santos ${ }^{1}$, Giulia Bessa Antoniaccio', Ticiane Cestari Fagundes'1, André Luiz Fraga Briso $^{1}$

'Departamento de Odontología Preventiva y Restauradora, Facultad de Odontología de Araçatuba - FOA / UNESP, Araçatuba, São Paulo, Brazil.

Introducción: se cree que la difusión del blanqueador está relacionada con el área de contacto del gel con la superficie dental. Pero esto aún no ha sido explorado en la literatura, estando todavía en el empirismo.

Objetivo: evaluar el efecto de la zona de aplicación del gel blanqueador sobre la alteración cromática y la sensibilidad postoperatoria.

Metodología: Se seleccionaron 30 pacientes (unidad experimental - caninos superiores), divididos en tres grupos, según el área de aplicación del producto $(n=20)$ : Gl-mitad cervical, Gll-mitad incisal, GIII-total vestibular, con peróxido de hidrógeno al 35\%. El análisis de color se realizó en un espectrofotómetro digital, con lecturas en las mitades cervical e incisal. El análisis de sensibilidad fue evaluado por un equipo de análisis neurosensorial; $y$ analizando cuestionarios utilizando la Escala Visual Analógica. Ambas pruebas se realizaron al inicio del estudio, después de la $1^{\mathrm{a}}, 2^{\mathrm{a}}, 3^{\mathrm{a}}$ sesión(s) y 7 días después del final, sometidas al modelo de regresión lineal y postest por contrastes ortogonales (5\%).

Resultados: Al evaluar la alteración cromática, tanto en el análisis cervical como en el incisal, el grupo que recibió el gel en su área de lectura mostró una diferencia estadística después de $1 \mathrm{~s}$, con influencia momentánea del sitio de aplicación. Sin embargo, después de $3 \mathrm{~s}$, todos los grupos mostraron similitud en el cambio de color. En cuanto a la sensibilidad, después de la 2s, GIII tuvo valores de sensibilidad más bajos y solo Gl informó sensibilidad espontánea.

Conclusión: la capacidad de difusión del gel blanqueador se produce de forma polidireccional, no dependiendo del contacto íntimo de la estructura dental con una alteración cromática homogénea. Además, la zona de aplicación del gel blanqueador puede influir en la respuesta de la sensibilidad dental. Financiamiento (Fapesp/ Br: 2018 / 11636-7) 


\section{Percepciones sobre cambios de enfoque en el sistema de pago odontológico en APS chilena}

Cynthia Cantarutti' ${ }^{1}$, Claudia Véliz' ${ }^{1}$, Lissette Betancourt ${ }^{1}$, Daniela Navarro', Javiera Novoa' ${ }^{1}$ Nicolas Olivares' ${ }^{1}$, Samuel Pulgar' ${ }^{1}$, Natalia Tornel ${ }^{1}$

'Escuela de Odontología, Facultad de Medicina, Pontificia Universidad Católica de Chile

Las enfermedades bucodentales son las que aportan una mayor carga por morbilidad en Chile y en el mundo. Actualmente, se sugiere un cambio del enfoque centrado en la enfermedad por un enfoque preventivo en base a controles periódicos centrado en las personas. En Chile, a nivel de atención primaria de salud, las metas odontológicas hasta el 2020 tenían un enfoque centrado en la enfermedad, basándose en cumplimiento de altas odontológicas existiendo un sistema de incentivos para el logro de ellas. Para las metas 2021 se presenta un cambio de enfoque y se plantea la pregunta: ¿Cuáles son las percepciones de los profesionales de la salud que trabajan en el área odontológica respecto a la implementación de un cambio en el sistema de pago de incentivos?

Se realizó un estudio cualitativo en el que se entrevistaron a odontólogos, técnicos en odontología y gestores, todos pertenecientes a la atención primaria de salud. La recolección de información fue mediante entrevistas individuales semiestructuradas. Las entrevistas fueron grabadas y transcritas para un posterior análisis de los resultados mediante codificación.

Tanto técnicos, cirujano dentistas y gestores presentan buena disposición frente al cambio de enfoque, pero con observaciones, como la necesidad de una mejor planificación al considerar que en la realidad chilena no se puede dejar de lado la atención de rehabilitación. Se requiere nueva evidencia que incorpore también los valores y preferencias de los pacientes respecto al cambio de enfoque.

\section{Reducción de aerosol en la clínica dental: Comparación de sistemas de aspiración}

\author{
Aldair León $\mathrm{T}^{1}$, Natalia Olmos V${ }^{1}$, Alvaro Guzmán $\mathrm{M}^{1}$ \\ 'Universidad Arturo Prat, Sede lquique.
}

La generación de aerosoles en la clínica odontológica como producto del uso de instrumental rotatorio o vibratorio representa un factor de riesgo en la transmisión de enfermedades infecciosas. La actual pandemia de COVID-19 ha puesto en evidencia la necesidad de reducir la presencia de aerosoles en la clínica odontológica.
En respuesta a esta necesidad, diversos sistemas de aspiración han salido al mercado y han tenido una importante demanda. Sin embargo, su efectividad en la reducción de aerosoles en la clínica odontológica no está claramente definida. El objetivo del presente estudio es comparar por detección fluorescente la efectividad en la reducción de aerosoles en la práctica odontológica de un grupo de sistemas de aspiración comerciales y de fabricación propia. En dos clínicas dentales simulamos situaciones de atención clínica convencionales, usando distintos sistemas de aspiración. El agua de refrigeración del instrumental rotatorio fue marcada con fluoresceína, y con posterioridad a las simulaciones se tomaron fotografías de alta resolución en el área de trabajo para cuantificar y comparar las superficies de diseminación del aerosol fluorescente. Todos los sistemas de aspiración analizados, a excepción del sistema De Bellis, redujeron significativamente la presencia de aerosol en las áreas perioperatorias, siendo relevante la distancia a la fuente de generación de aerosol. Nuestros resultados permiten sugerir el uso de sistemas de aspiración como ayudante en la prevención de enfermedades infecciosas en la clínica odontológica.

\section{Vitamina D como factor de riesgo para pérdida dentaria: ENS 2016-2017}

Diego Lohmann Cañete', Claudio Carrasco Mococain ${ }^{1}$, Francisco

Moreno Ferrer', Juan Vargas Buratovic', Claudia Véliz', Duniel Ortuño Borroto ${ }^{1}$

'Escuela de Odontología, Facultad de Medicina, Pontificia Universidad Católica de Chile.

Objetivo: La Encuesta Nacional de Salud 2016-2017 es el primer estudio poblacional en Chile en medir los niveles de vitamina D. Por ello, el objetivo de este estudio fue evaluar la asociación entre los niveles sanguíneos de vitamina $\mathrm{D}$ y la pérdida dentaria en población adulta no institucionalizada (>15 años).

Métodos: Se incluyeron 2859 sujetos, participantes de la Encuesta Nacional de Salud Chile 2016-2017 (ENS 2016-2017), que corresponden a la submuestra en las cual fue medida los niveles de vitamina D. Se utilizaron como puntos de corte para la variable: $<11,99$, $12-19,99,20-29,99$ y > $30 \mathrm{ng} / \mathrm{ml}$. El déficit severo de vitamina $D$ se consideró como $<11,99 \mathrm{ng} / \mathrm{ml}$. La pérdida de dientes fue determinada mediante examen intraoral por enfermeras (kappa=0,85, valor-p<0.001), determinando el número de dientes y edentulismo. Para las variables numéricas se utilizaron regresiones lineales, mientras que para desenlaces categóricos se hicieron regresiones logísticas. Se consideraron como variables de ajuste la edad, sexo, zona (urbano/rural) y nivel educacional (NEDU). Se consideró una significancia de 0.05. Los análisis se hicieron en SPSS, módulo de muestras complejas. 
Resultados: Se encontró una asociación estadísticamente significativa entre el número de dientes y los niveles de vitamina $D$ (valor $\mathrm{p}<0.001)\left(\mathrm{R}^{2}=0,66\right)$. Los sujetos con niveles de $<11,99 \mathrm{ng} /$ $\mathrm{ml}$ tuvieron en promedio 20,15 dientes (se $=0.62$ ), mientras que sujetos con $>30 \mathrm{ng} / \mathrm{ml}$, alcanzaban 22,21 dientes (se=0.64). Los sujetos con niveles $<11,99 \mathrm{ng} / \mathrm{ml}$ tenían 2,05 (OR) más chance de pérdida dentaria de perder al menos un diente comparado con aquellos con >30 ng/ml (IC 95\%: 1,01-4,16); mientras que en edentulismo el OR fue de 2,97 (IC 95\%: 1,31-6,74).

Conclusiones: Los bajos niveles de vitamina $D$ se asociaron a un menor número de dientes en individuos adultos, independiente de la edad, sexo, zona y NEDU, particularmente en el grupo con deficiencia severa de vitamina D. 


\section{Casos clínicos}




\section{Enucleación de Quiste dental en región anterior de maxila en paciente pediátrico}

Patrícia Sthefânia Mulatinho Paiva', Kleyciane Kévlin Pereira da Silva', Ricardo Eugenio Varela Ayres de Melo'

${ }^{1}$ Centro Universitario Facol (UNIFACOL), Vitória de Santo Antão-Pernambuco, Brasil.

El quiste dentígero es el tipo más común de quistes odontogénicos del desarrollo y el segundo más común entre todos los que ocurren en los maxilares, representando alrededor del $20 \%$ de todos los quistes revestidos por epitelio en los huesos gnáticos. Clínicamente, puede asociarse con cualquier diente impactado, pero con mayor frecuencia afecta a los terceros molares inferiores. Suele afectar a pacientes entre 10 y 30 años y existe una ligera predilección por el sexo masculino y una mayor prevalencia en blancos que en negros, en la mayoría de los casos se detectan en exámenes radiográficos de rutina. El presente trabajo tiene como objetivo reportar el caso clínico de una paciente de 07 años de edad que presentó quiste dentígero en la región anterior del maxilar izquierdo. La paciente, acompañada de su progenitor, acudió al Servicio de Cirugía y Traumatología Maxilofacial Buco de la Universidad Federal de Pernambuco, informando la ausencia del incisivo central, lateral y canino superior izquierdo. El examen de imagen mostró una imagen unilocular radiolúcida que involucraba elementos dentales permanentes. El paciente fue remitido al quirófano para realizar la enucleación quística de la lesión, con escisión de los dientes incluidos, bajo anestesia general. El tratamiento realizado en el paciente fue favorable según la literatura, por lo que la enucleación cuando se indica correctamente y se realiza con cuidado, constituye una modalidad terapéutica sumamente viable en el tratamiento del quiste dentígero por el reducido riesgo de recurrencia.

\section{Extirpación de Sialolitos Inusuales en Conducto Submandibular con Láser de Diodo. Caso Clínico}

Belén Hernández Muñoz \& Patricio Rubio Palma $a^{2-3-4}$

'Universidad de Talca, Facultad Ciencias de la Salud, Escuela de Odontología. ${ }_{2}^{2}$ Servicio de Salud Concepción, Hospital Guillermo Grant Benavente,

Patólogo Oral.

${ }^{3}$ Desarrollo privado de la Especialidad.

${ }^{4}$ Docente Postgrado UNAB-UDD.

Introducción: El sialolito es un depósito cálcico común de las glándulas salivales mayores, caracterizado por la obstrucción del parénquima o conducto excretor de estas. Suele medir de $1 \mathrm{~mm}$ a $10 \mathrm{~mm}$, con menor frecuencia miden más de $15 \mathrm{~mm}$.
El uso de láser de diodo de alta potencia contribuye a un abordaje quirúrgico no invasivo, mínimo sangrado y mayor comodidad para el paciente.

Reporte de Caso: Paciente masculino de 32 años, no relata patologías de base, consumidor social de alcohol y ex fumador. Consulta por lesión bajo la lengua, relatando evolución desde hace 3 años, acentuándose el crecimiento los últimos meses. Al examen clínico se visualiza aumento de volumen de $15 \mathrm{~mm}$ aprox. en zona derecha de piso de boca de consistencia dura. Diagnóstico presuntivo: Sialolitiasis.

Se solicita conebeam y exámenes preopertorios. Se realiza abordaje mínimo con láser de diodo con potencia de $1.5 \mathrm{~W}$ en modo continuo, obteniendo excelente control de hemostasia. Se envían muestras de $15 \times 12 \times 9$ mm y 12×8×9 mm para análisis histopatológico, confirmándose el diagnóstico de sialolitiasis submandibular. Se realiza control a las 4 semanas sin complicaciones.

Relevancia Clínica: El sialolito causa incomodidad e inquieta al paciente por su aspecto y consistencia. Es importante explicar al paciente su característica benigna.

Lo particular del caso es la extensión de las lesiones, dado que, la evidencia científica describe tamaños menores y en solitario. Además, el manejo quirúrgico mediante láser de diodo obtiene nulo sangrado y menor incomodidad para el paciente, a diferencia de la escisión con bisturí que se realiza convencionalmente.

Conclusión: Los sialolitos mayores a $15 \mathrm{~mm}$ son inusuales. Es deber del odontólogo el correcto diagnóstico y posterior derivación para tratamiento de la lesión. El uso de laserterapia logra un campo quirúrgico limpio, mínimo dolor y menor disconfort postquirúrgico en el paciente, lográndose una pronta cicatrización.

\section{Extrusión quirúrgica en ausencia de margen supragingival. Caso Clínico}

Jean-Pierre Jouanet Arias' ${ }^{1}$ Camilo Andrés Labra Millaqueo'

'Universidad Mayor Temuco.

Introducción: La extrusión quirúrgica es el procedimiento donde el diente se reposiciona más supragingival en la misma cavidad en que se encontraba originalmente. Este punto es importante para poder realizar una buena restauración, que mantenga saludable el ancho biológico.

Un resumen de los pasos principales involucrados en la técnica descrita es: sindesmotomía, luxación del diente usando elevadores, extrusión de la raíz con fórceps, inmovilización de la raíz durante dos o tres semanas en la nueva posición usando una férula flexible o suturas interdentales, para la posterior restauración final. 
Reporte del caso: Paciente de 40 años, mordida borde a borde, sufre la fractura de diente 2.2 en sentido transversal de vestibular a palatino, con marcada movilidad del fragmento coronario y tratamiento endodóntico previo.

Posterior al retratamiento endodóntico, cementación de poste de cuarzo y tallado, se procede a desinfectar el área comprometida con clorhexidina al $0.12 \%$, anestesia infiltrativa y sindesmotomía, luxación con un elevador fino en los primeros $4-5 \mathrm{~mm}$ de la estructura radicular. Una vez que el diente se desprende del alveolo se extruye $3 \mathrm{~mm}$ con fórceps recto fino.

Se aplicó presión en sentido vestíbulo - palatino, previo a la ferulización con una resina fluida durante 10 semanas.

La prótesis fija se realizó 3 meses y medio después de la intervención para lograr la correcta cicatrización de los tejidos periodontales y evitar una migración gingival postoperatoria, rehabilitando en Disilicato de litio.

Conclusiones: La extrusión quirúrgica es una alternativa terapéutica con una tasa de éxito alta. Este procedimiento permite una posterior restauración sin necesidad de alargamiento coronario ni aparatología ortodóncica. Clínicamente el diente se encuentra asintomático, sin movilidad y manteniendo sus funciones estéticas y biológicas. Finalmente, no se debe obviar la cantidad de evidencia respecto al procedimiento, considerándolo una opción viable frente a sus homólogos más invasivos/costosos.

\section{Manifestaciones periodontales de la Granulomatosis de Wegener: Un caso clínico}

\author{
Natalia Tornel' ${ }^{1}$ Alejandro Marín' ${ }^{1}$, Patricio Smith \\ 'Escuela de Odontología, Facultad de Medicina, Pontificia Universidad \\ Católica de Chile.
}

La granulomatosis de Wegener o granulomatosis con poliangitis (GPA) es una enfermedad que se caracteriza por inflamación y necrosis de las paredes de los vasos sanguíneos. Es de etiología desconocida y baja prevalencia (23,7-156,5/1.000.000) pero de alta agresividad. La edad promedio al diagnóstico en Chile es de 50,8 $\pm 14,03$ años y no hay diferencia por sexo. Si bien la GPA puede afectar múltiples sistemas y órganos, los más comúnmente afectados son: vía aérea superior, pulmones y riñones. Esta enfermedad presenta manifestaciones en la cavidad oral. Una de las más comunes, es en la región anterosuperior de las encías. A esta afectación se le conoce como gingivitis de fresa, la cual es un signo característico de GPA. Esta gingivitis se manifiesta con un agrandamiento y eritema de las papilas interdentales que generalmente parte de forma localizada, pero puede llegar a afectar labios, lengua y hueso alveolar. Con estos antecedentes, se reporta el caso de un paciente sexo masculino, 34 años, ASA I que acude derivado el 2018 a especialista en periodoncia en una clínica particular en Santiago de Chile. El paciente manifiesta un aumento de volumen de la encía de características inflamatorias que compromete encía adherida y libre y que cubre $3 / 4$ de la corona de dientes del grupo V. Además presenta periodontitis crónica incipiente. La lesión gingival es eliminada quirúrgicamente. La histopatología muestra una lesión inflamatoria con gran infiltración neutrofílica y vasos sanguíneos dilatados. El paciente es derivado al otorrinolaringólogo quien detecta lesiones inflamatorias en fosas nasales. Reumatólogo diagnostica Granulomatosis de Wegener luego del examen clínico y examen ANCA a nivel sanguíneo. El paciente fue tratado con metotrexato y corticoesteroides. Un año después el paciente se encuentra sano, sin manifestaciones del Wegener y los tejidos periodontales se encuentran sanos, libres de inflamación.

\section{Sindrome de hipoglosia-hipodactilia, presentación de un caso clinico}

\author{
Camila González', Alonso Etcheverry' ${ }^{1}$ Araceli Raposo²
}

'Estudiante de Pregrado, Facultad de Odontología, Universidad de Chile. 2Departamento de Cirugía y Traumatología Oral y Maxilofacial, Universidad de Chile.

Introduccion: El Síndrome de hipoglosia - hipodactilia es un síndrome congénito extremadamente infrecuente. Las personas afectadas presentan aglosia o microglosia, adactilia y otras malformaciones craneofaciales y de extremidades.

A nivel craneofacial se ha relacionado a alteraciones en la forma de la mandíbula, tales como la forma del arco mandibular en $\mathrm{V}$ y retrognatismo acompañado de un escaso desarrollo de la lengua, por lo que funciones vitales como habla, masticación y deglución, se ven afectadas.

Reporte de caso: Paciente de 17 años, sexo masculino, diagnosticado con Síndrome Hipoglosia - Hipodactilia, se encuentra en tratamiento de ortodoncia hace 4 años y es derivado para cirugía ortognática. Al examen físico se obseva sindactilia en mano izquierda, adactilia en ambos pies, perfil facial Clase II con retrusión mandibular marcada. Intraoralmente se constata microglosia y agenesia de incisivos inferiores, con contacto de caninos en línea media, overjet de $12 \mathrm{~mm}$ y relación molar y canina Clase II de Angle. Se realiza una búsqueda sobre alternativas de tratamiento. 
Discusión: Se han descrito casos sobre pacientes con Síndrome Hipoglosia -hipodactilia, los cuales han sido tratados con distracción osteogénica durante su período de crecimiento, con resultados favorables a largo plazo, reduciendo la necesidad de intervenciones quirúrgicas mayores.

En pacientes que han finalizado su etapa de crecimiento se han realizado tratamientos de ortodoncia y técnicas de expansión mandibular graduales, para luego ser intervenidos con cirugía ortognática logrando estabilidad oclusal.

Otras cirugías complementarias son la genioplastía y la queiloplastía, las cuales son realizadas para mejorar los rangos de movimiento de la lengua y labios, los cuales acompañados de terapias como fonoaudiología pueden mejorar aspectos funcionales.

Conclusión: En el ámbito odontológico/quirúrgico, este síndrome constituye un desafío debido a la escasa información sobre las alternativas de tratamiento y la complejidad de resolución de los casos desde el punto de vista funcional y estético.

\section{Tratamiento de osteomielitis tras la fractura mandibular derivada de extracción del tercer molar}

Luis Fellipe Moraes Castello', Zilma Ribeiro do Nascimento ${ }^{1}$ Ricardo Eugenio Varela Ayres de Melo ${ }^{1}$

'Universidade Federal de Pernambuco (UFPE). Recife, Pernambuco, Brasil.

Introducción: La aparición de fracturas mandibulares después de la extracción de terceros molares inferiores son complicaciones raras y graves. Entre los factores de riesgo se encuentran la edad avanzada del paciente y el grado de osteotomía. Cuando se descuida, puede convertirse en pseudoartrosis, lo que requiere una cirugía abierta para eliminar el tejido fibroso o infectado y una fijación interna rígida entre los muñones fracturados. Si no se trata, se puede desarrollar osteomielitis debido al cambio en la vascularización ósea. El diagnóstico es clínico, radiográfico e histológico. El tratamiento se basa en legrado y antibioterapia.

Reporte de caso: Paciente de sexo femenino de 40 años que presentó una fractura de mandíbula durante la extracción del elemento 38 semicerrado mesioinclinado, que no fue identificado por el profesional. Acudió a la Clínica de Cirugía y Traumatología Oral y Maxilofacial de la Universidad Federal de Pernambuco quejándose de dolor, que clínicamente mostraba movilidad entre los muñones óseos, edema y supuración en la región de extracción, siendo diagnosticada de osteomielitis crónica con periostitis proliferativo.
Las imágenes radiográficas mostraron un aspecto de esclerosis densa con apariencia de "piel de cebolla". El tratamiento recomendado fue el legrado del alveolo y la región adyacente y la eliminación de los focos de la infección, seguido de la fijación interna rígida con 1 placa con 4 tornillos para la fractura. El posoperatorio incluyó antibioterapia que, a los 12 días, sin complicaciones, se retiró la sutura y se observó mejoría clínica.

Conclusiones: Las fracturas mandibulares deben tratarse con reducción e inmovilización adecuada para evitar el desarrollo de un proceso infeccioso. Cuando se instala osteomielitis, el tratamiento consiste en eliminar el factor etiológico y la cobertura antibiótica y tiene un pronóstico favorable.

\section{Tratamiento quirúrgico de hiperplasia fibrosa en seno maxilar causada por un cuerpo extraño}

Luana Maria de Moura Santos ${ }^{1}$, Rodrigo Henrique Mello Varela

Ayres de Melo ${ }^{1}$, Ricardo Eugenio Varela Ayres de Melo ${ }^{1}$

${ }^{1}$ Centro Universitário Facol (UNIFACOL), Vitória de Santo Antão, Pernambuco - Brasil.

Introducción: La hiperplasia fibrosa es una lesión caracterizada por la formación de tejido epitelial y tejido conectivo fibroso en respuesta a traumas crónicos o irritaciones locales. Se localiza frecuentemente en regiones próximas al borde alveolar, mucosa Yugal, lengua y labio inferior, pudiendo presentar localizaciones atípicas, como el seno maxilar. El objetivo del presente trabajo es informar el caso clínico de un paciente afectado por hiperplasia fibrosa en seno maxilar izquierdo, causada por cuerpo extraño.

Reporte de caso: El paciente compareció al Servicio de Cirugía y Traumatología Buco Maxilo Facial de la Universidad Federal de Pernambuco quejándose de una secreción de olor fétido, que sale por las cavidades nasal y oral. Durante la anamnesis él relató haber realizado en otro servicio una cirugía de descompresión en el sitio afectado hace aproximadamente siete años y, después de recibir el alta hospitalaria, no regresó para la reevaluación. Al examen clínico intrabucal se observó una lesión hiperplásica, normocrómica, envolviendo un cuerpo extraño en la región de seno maxilar izquierdo. Se realizó una biopsia incisional de la lesión, obteniéndose el diagnóstico de Hiperplasia Fibrosa. Se preconizó el tratamiento quirúrgico, utilizando la técnica de Caldwell-Luc para acceder a la región de seno maxilar. La cirugía continuó con la extirpación del cuerpo extraño y la resección de la lesión. el postoperatorio transcurrió sin incidentes. El paciente continúa en seguimiento y al año no presenta signos de recurrencia de la patología. 
Conclusiones: Por tanto, es evidente que la correcta orientación y el apoyo postoperatorio son de suma importancia. La técnica de Caldwell-Luc permite fácil acceso al seno maxilar y su uso es frecuentemente descrito en la literatura para remoción de cuerpos extraños, así como, para el tratamiento de procesos patológicos en la región.

\section{Tratamiento quirúrgico de la sinusitis maxilar de origen odontogenico mediante la técnica Caldwell-Luc}

Deise Louise Bohn Rhoden', Lohana Maylane Aquino Correia de Lima', Ricardo Eugenio Varela Ayres de Melo

'Universidad Federal de Pernambuco (UFPE). Recife, Pernambuco - Brasil.

Introducción: El seno maxilar puede verse afectado por varios procesos patológicos recurrentes del seno, entre ellos la sinusitis de origen odontogénico. Esta patología presenta hiperplasia o inflamación en la mucosa de revestimiento de los senos asociados a un elemento dentario necrótico. Se ha sugerido la técnica de Caldwell-Luc como un medio de acceso al seno maxilar, ya que permite su inspección y tratamiento de las enfermedades que lo afectan.

Reporte del caso: Paciente, 57 años, sexo femenino, leucodermia; quien acudió a la Clínica Buco de Cirugía Maxilofacial y Traumatología del Hospital das Clínicas de la Universidad Federal de Pernambuco, quejándose de cefalea constante, edema en la región periorbitaria izquierda y sinusitis crónica. El examen de imagen del tipo de radiografía panorámica mostró la ausencia de múltiples elementos dentales con dos dientes incluidos: uno en la región anterior del maxilar derecho y otro en la región posterior de la mandíbula izquierda, con imágenes radiolúcidas rodeando las coronas del mismo, con hipótesis diagnósticas de quistes dentígeros. En el suelo del seno maxilar izquierdo se encontró una alteración radiopaca homogénea en forma de cúpula. El tratamiento del paciente se basó en la realización de sinusectomía maxilar izquierda de origen odontogénico y exéresis del canino superior derecho y tercer molar inferior izquierdo, ambos incluidos. La cirugía se realizó bajo anestesia general para la enucleación del quiste en el seno maxilar mediante la técnica quirúrgica de Caldwell-Luc.

Conclusión: Se concluye, por tanto, que en la sinusitis maxilar de origen odontogénico, el tratamiento clínico de elección será la enucleación quística de toda la lesión mediante la técnica quirúrgica de Caldwell-Luc.

\section{Tratamiento quirurgico del lipoma submandibular grande}

Kleyciane Kévilin Pereira da Silva' ${ }^{1}$ Patrícia Sthefânia Mulatinho Paiva', Ricardo Eugenio Varela Ayres de Melo'

'Centro Universitario Facol (UNIFACOL), Vitória de Santo Antão-Pernambuco, Brasil.

El lipoma es un tumor benigno de origen mesenquimatoso de etiología incierta, situado en la capa adiposa o submuscular y compuesto por tejido adiposo. Tiene predilección por el hombre, entre los 50 y 70 años, siendo el tronco y las extremidades las localizaciones más frecuentes y el tratamiento de elección es la resección quirúrgica conservadora. Este estudio tiene como objetivo reportar el caso de tratamiento quirúrgico de lipoma extenso en región submandibular en una paciente de 67 años, que presentó aumento de volumen en región submandibular derecha, con 5 años de evolución. En el examen clínico la lesión estaba bien definida, móvil, suave al tacto e indolora. Se recomendó una biopsia por escisión. Bajo anestesia general se realizó incisión submandibular de Risdon, con el objetivo de preservar la rama de jaffé, divulgación de tejidos subcutáneos y hemostasia de vasos sangrantes. La cirugía continuó con la resección de la lesión, sanado de la cavidad y sutura en capas. La pieza patológica fue enviada al Servicio de Anatomopatología del Hospital das Clínicas, Universidade Federal de Pernambuco, de 14 × 6,5 cm, con confirmación de la hipótesis de Lipoma. El caso fue seguido durante seis años, mostrando buenos resultados estéticos y funcionales sin recurrencia. Por tanto, aunque no sea muy frecuente en la región de cabeza y cuello, le corresponde al Cirujano Oral Maxilofacial conocer las características de este tipo de patología, así como el manejo adecuado. El tratamiento de elección fue la resección quirúrgica total de la lesión ya que presenta un pronóstico favorable y evitar recidivas. El abordaje submandibular de Risdon resultó ser una buena opción para las lesiones de la región cervical, ya que cuando se realiza correctamente, evita lesiones en estructuras anatómicas importantes de la región, además de presentar un resultado estético satisfactorio. 
Revisiones Bibliográficas 


\section{Ley de Etiquetado Nutricional de Chile: Impacto en el consumidor}

\author{
Javiera Novoa' ${ }^{1}$ Francisco Moreno' ${ }^{1}$, Camila Olivares ${ }^{1}$, Claudio \\ Carrasco', Frobel Delgado', Valentina Notebaert ${ }^{1}$, Lucas \\ Martinez ${ }^{1}$ y Rosario García-Huidobro' ${ }^{1}$ (T) \\ 'Escuela de odontología, Facultad de Medicina, Pontificia Universidad \\ Católica de Chile.
}

Introducción: La obesidad es un padecimiento que afecta la calidad de vida de las personas y ha ido en aumento con el paso de los años, de tal forma que se han tenido que tomar medidas para combatir esta afección tanto a nivel mundial y nacional. Una de las medidas que implementó Chile es la ley de etiquetados que añade sellos "ALTO EN" a los alimentos según corresponda.

Material y Métodos: Se realizó una revisión narrativa para identificar el impacto que han generado estas medidas en el país a nivel de los consumidores y se examinaron diferentes metodologías internacionales para dar a conocer posibles mejoras al sistema nacional. Se utilizaron las siguientes bases de datos: Google académico, PubMed y Epistemonikos realizando la búsqueda con los términos claves "impacto" "etiquetado nutricional", "Chile", "Food

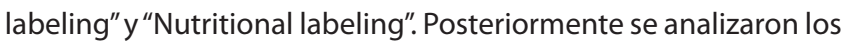
datos y resultados de artículos en inglés y español, publicados con fecha 2014 y posterior.

Resultados: Se observó que el formato implementado para entregar la información sí es efectivo. Esto se refleja en que el 92,9\% de las personas afirma entender los sellos. En relación al impacto en la decisión de compra se observó que un 48,1\% de los encuestados compara los sellos de advertencia y de estos el 79,1\% indica que influye en su decisión de compra. Respecto a las metodologías internacionales, se comparó la que más se repetía (sistema de semáforo) con la de peligro que se emplea en Chile, concluyendo que esta última es más efectiva.

Conclusión: La implementación del etiquetado nutricional chileno sí ha tenido un impacto significativo en la población con respecto a las percepciones y conductas al momento de comprar. Sin embargo, aún tiene que aumentar su cobertura e influencia sobre los consumidores. Se sugieren estudios posteriores para evaluar impactos futuros.

\section{Endodoncia guiada: Una revisión narrativa}

Massiel, Macarena', Ottesen, Frank', Orellana, Andrea', Salazar, Daniela $^{2}(\mathrm{~T})$.

'Estudiante de Pregrado, Facultad de Odontología, Universidad de Chile. 2Departamento Odontología Conservadora, Facultad de Odontología, Universidad de Chile

Introducción: La endodoncia guiada (EG) es una innovadora técnica conservadora de acceso al canal radicular en dientes calcificados (DC) o con malformaciones. Para la EG se requiere una tomografía computarizada cone-beam (CBCT), lo cual permite crear una guía quirúrgica impresa en 3D y determinar el posterior abordaje en el canal radicular con fresas.

Objetivo: Presentar un método novedoso de acceso al canal radicular en DC o malformaciones con sus aplicaciones clínicas, precisiones y limitaciones.

Metodología: Búsqueda de la literatura en bases de datos Pubmed, Embase, Scopus y de forma manual con las siguientes palabras claves: "guided endodontics" AND "3D printed teeth" AND root canal treatment" entre los años 2016 a 2021. No se consideraron artículos no atingentes al tema, duplicados y revisiones sistemáticas.

Resultados: Se incluyeron un total de 17 artículos (estudios transversales, reportes de caso y estudios in vitro). En general, los estudios utilizan un CBCT y con ayuda de un software, fabrican una guía impresa en 3D para acceder al canal radicular y realizar el tratamiento endodóntico.

Discusión: Todos los artículos analizados describen la EG como una técnica de alta precisión, que minimiza el desgaste en los tejidos, reduce la iatrogenia y tiempo clínico en comparación a una técnica de endodoncia convencional en DC y con malformaciones. Sin embargo, hay que considerar el costo asociado y que solo se puede realizar en canales radiculares rectos o porciones rectas en canales curvos

Conclusión: La literatura actual respalda el uso de esta técnica confiable y segura en el tratamiento de DC y en variaciones anatómicas, junto con requerir menos tiempo en el sillón y mejorar el pronóstico de los dientes. Pese a lo antes mencionado, se debe tener en consideración sus limitaciones ya que la evidencia utilizada se basa en estudios in vitro, reportes de caso y estudios observaciones. 


\section{Métodos de higiene oral en la prevención de Neumonía asociada a Ventilación Mecánica, revisión sistemática}

\author{
Muñoz E. ${ }^{1}$, Ruiz-Silva C. ${ }^{1}$, Pesenti P. ${ }^{1}$, Bravo C. ${ }^{2}$ \\ 'Licenciado en Odontología, Universidad de Concepción, Chile. \\ ${ }^{2}$ Cirujano Dentista, Especialista en Cirugía y Traumatología Maxilofacial, \\ Universidad de Concepción.
}

La neumonía asociada a ventilación mecánica (NAVM) corresponde a una infección pulmonar inflamatoria de origen nosocomial que se desarrolla en pacientes ventilados mecánicamente, al menos 48 horas después de la intubación. Es una de las principales infecciones en la unidad de cuidados intensivos. La cavidad oral tendría un rol importante en el desarrollo de ésta, ya que se comportaría como un reservorio de patógenos bacterianos respiratorios, debido a que durante la intubación orotraqueal se produce un cambio en la microbiota oral. Por esto, la higiene oral toma un rol importante en la prevención de la misma. Siguiendo declaración PRISMA, se realizó revisión sistemática sobre métodos de higiene oral para la prevención de NAVM en PubMed, Web of Science, Cochrane Library y Scielo utilizando como algoritmo de búsqueda: (Oral Hygiene OR dental health OR dental care) * AND (mechanic Ventilation) AND (ventilator associated pneumonia $O R$ ventilator associated tracheobronchitis) incluyéndose artículos entre 2015-2020, de idioma inglés-español y que respondan a los objetivos. La selección de los artículos se hizo entre pares. Se encontraron 120 artículos, 34 se seleccionaron para análisis cualitativo. Los resultados se describieron en tabla: autor/ año/país, diseño del estudio, intervención y resultados. La literatura demuestra que existe una variedad de sustancias usadas en la higiene oral de pacientes intubados como lo son: peróxido de hidrógeno, povidona yodada, antibióticos y clorhexidina siendo esta última la más usada, algunos estudios concluían que éstos se potenciarían con uso del cepillo dental. El cuidado oral en pacientes intubados es una problemática común y la ausencia de protocolos agrava esto, por lo que el Odontólogo debe tener un rol activo y participativo.

\section{Adenocarcinoma Polimorfico Oral: Características Clínicas, Diagnóstico y}

\section{Tratamiento}

Rodrigo Henrique Mello Varela Ayres de Melo', Camilla Siqueira de Aguiar'; Deise Louise Bohn Rhoden', Milena Mello Varela Ayres de Melo Pinheiro', Nely Dulce Varela de Melo Costa Freitas', Jussara Diana Varela Ayres de Melo1', Victor Leonardo Mello Varela Ayres de Melo', Ricardo Eugenio Varela Ayres de Melo

${ }^{1}$ Universidad Federal de Pernambuco (UFPE). Recife, Pernambuco, Brasil.
Introducción: El adenocarcinoma polimorfo es un tumor epitelial maligno caracterizado por uniformidad citológica, diversidad morfológica, patrón de crecimiento infiltrativo y bajo potencial metastásico

Objetivo: discutir cómo se realizan las características clínicas, los diagnósticos y los tipos de tratamientos para el adenocarcinoma polimorfo que se encuentra en la cavidad oral.

Metodología: Se trata de una revisión integradora de la literatura que se realizó una búsqueda en las bases de datos con los descriptores: Adenocarcinoma, Neoplasia maligna, Glándula salival con restricción de tiempo de los últimos 5 años. Los criterios de inclusión fueron artículos completos y en idioma inglés. Se excluyeron los trabajos publicados en los anales de hechos y cartas al editor.

Resultados: Se seleccionaron 18 artículos para formar parte de este estudio. Esta condición ha sido reportada como la segunda neoplasia maligna de glándulas salivales más frecuente y representa aproximadamente del $17,3 \%$ al $26,4 \%$ de todas las neoplasias malignas de las glándulas salivales menores y es más frecuente entre las mujeres mayores entre la sexta y la octava décadas de la vida. Clínicamente, la lesión puede presentarse en la cavidad oral de la siguiente manera: difícil de palpar; ampliación de la región; nódulo asintomático; crecimiento lento; ulceración de la mucosa de revestimiento; y localmente infiltrante. Los sitios afectados con mayor frecuencia son el paladar duro y el paladar blando. El tratamiento de elección para el adenocarcinoma polimórfico descrito en la literatura médica es la escisión quirúrgica extensa con márgenes, comúnmente incluyendo la resección del hueso subyacente, con posibilidad de combinación con radioterapia.

Conclusiones: El adenocarcinoma polimórfico es una neoplasia maligna rara que afecta a las glándulas salivales cuyo potencial de malignidad, recidiva y metástasis, es relativamente bajo. Con base en los casos descritos en la literatura médica, la escisión quirúrgica con márgenes de seguridad es el procedimiento de elección.

\section{Asociación de periodontitis y osteoporosis en mujeres posmenopáusicas}

Orellana, Andrea' ${ }^{1}$ Ojeda, Gabriel' ${ }^{1}$, Matamala, Loreto ${ }^{2}$

'Estudiante de Pregrado, Facultad de Odontología, Universidad de Chile.

${ }^{2}$ Departamento Odontología Conservadora, Facultad de Odontología, Universidad de Chile 
Introducción: La osteoporosis (OP) es una enfermedad esquelética que se caracteriza por la disminución de masa ósea y altamente prevalente en mujeres posmenopáusicas (MP) debido a cambios hormonales. La disminución de estrógeno influye en el remodelado óseo ya que hay un aumento de la reabsorción ósea y de los osteoclastos. La periodontitis (PE) se caracteriza por la pérdida ósea y esta podría verse influenciada con la presencia OP.

Objetivo: Determinar si existe asociación entre la PE y OP en MP

Metodología: Búsqueda bibliográfica en PUBMED, EBSCOhost, Scopus y Scielo con los términos: "postmenopause" AND "osteoporosis" AND "periodontitis", del año 2016 a 2021 en inglés, español y portugués. Se excluyeron revisiones, artículos duplicados y no relacionados con el tema.

Resultados: Se incluyeron 12 estudios observacionales transversales, que midieron densidad ósea y parámetros periodontales.

Discusión: Aunque no existe consenso en que haya una asociación significativa entre OP y $P E, 10$ artículos concluyen que la OP puede ser un indicador de riesgo y posiblemente un factor que conduce a una condición periodontal más severa en MP. Hay evidencia que sostiene un efecto directo entre mujeres con OP y el aumento en la progresión de la destrucción del tejido periodontal. Debido a esta correlación, se observó que el tratamiento de la OP tiene efectos protectores para la PE, ya que MP sin tratamiento de OP presentaban PE en grados más severos.

Conclusión: La OP puede tener un impacto en la condición periodontal y podría ser un indicador de riesgo de periodontitis en MP. Se sugiere que MP con diagnóstico de OP, deben ser evaluadas por odontólogos para prevención, detección y tratamiento oportuno de la PE. Sin embargo, es necesario el desarrollo de ensayos clínicos para respaldar una asociación significativa.

\section{Asociación entre accidentes cardiovasculares y calcificaciones de arterias carótidas observadas en radiografías panorámicas}

Dominique Fica S. ${ }^{1}$, Vicente Rivano N. ${ }^{1}$, Constanza Neira U. ${ }^{1}$

'Universidad del Desarrollo, Sede Concepción.

Introducción: La aterosclerosis es una enfermedad vascular que disminuye el flujo sanguíneo, predisponiendo a accidentes cerebrovasculares por la formación a nivel de la arteria carótida de placas ateromatosas, las que al calcificarse pueden ser vistas en radiografías panorámicas.
Objetivo: Determinar la relación entre la calcificación de arterias carótidas observadas en radiografías panorámicas con accidentes cardiovasculares.

Metodología: Se realizó una búsqueda en Cochrane library, Elsevier, MDPI, Nature, PubMed y Springer, utilizando las palabras clave Carotid Arteries, Calcification y Panoramic radiography empleando sus respectivos términos MeSH con operadores booleanos AND y OR, con filtro por los últimos 5 años.

Resultados: Se obtuvo como resultado 129 elementos, sólo 27 cumplieron los criterios de inclusión. Los pacientes que poseen calcificaciones en las arterias carótidas detectadas en radiografías panorámicas presentan un riesgo de sufrir eventos cardiovasculares como accidentes cerebrovasculares, infarto al miocardio, cardiopatías isquémicas o anginas, asociado a factores de riesgo como tabaquismo, obesidad, diabetes, hipertensión, cirrosis hepática, edad avanzada y ser mujer.

Discusión: Las radiografías panorámicas no son los mejores exámenes para evaluar la presencia de calcificaciones de la arteria carótida, pero son de gran utilidad para indicar riesgo de futuros eventos cardiovasculares y detectar hallazgos en pacientes asintomáticos o con un nivel de riesgo cardiovascular previamente desconocido.

Conclusión: La calcificación de las arterias carótidas observadas en radiografías panorámicas presenta estrecha relación tanto con accidentes cardiovasculares como con factores de riesgo de los mismos, por lo que el odontólogo debe estar en conocimiento de estos hallazgos incidentales y considerar la posibilidad de derivar a estos pacientes.

\section{Asociación entre obesidad y caries dental en niños y adolescentes: Una Revisión Sistemática}

Ampuero, Paula' ${ }^{1}$ Alvarez, Sebastián' ${ }^{1}$, Cortez, Ruben²

'Estudiante de Pregrado, Facultad de Odontología, Universidad de Chile. ${ }^{2}$ Departamento de Pregrado, Facultad de Odontología, Universidad de Chile.

Introducción: La caries dental y el sobrepeso son afecciones frecuentes en niños y adolescentes que afectan su salud y bienestar, generando consecuencias sistémicas prevenibles. Estas comparten factores de riesgo, pero su asociación es contradictoria. Esta definición podría conducir a esfuerzos conjuntos de prevención y promoción de salud. El objetivo del trabajo es evaluar la existencia de una relación entre la presencia de lesiones de caries y obesidad en niños y adolescentes. 
Materiales y Métodos: Se realizó una revisión sistemática en las bases de datos Pubmed, Embase, Ebscohost y Web of Science, utilizando los términos "((obesity) AND (child)) AND (dental caries)". Se incluyeron publicaciones en revistas con comité editorial, números regulares y revisión de pares ciegos o indexadas, publicadas entre 2016-2021; sin restricción idiomática, ni de género. Se excluyeron estudios secundarios, duplicados y revisiones.

Resultados: La selección final incluyó 23 artículos que evaluaron la relación Caries-Obesidad infantil, leídos in extenso. El 61\% de los estudios fueron realizados en países de Asia. Los instrumentos de evaluación fueron COPD e IMC, adicionalmente en el $55 \%$ de ellos se incluyeron medidas antropométricas, ICDASy cuestionarios de dieta e higiene oral.

Discusión: El 60.8\% de los estudios no encontró una asociación entre obesidad infantil y caries, mientras que el $39.2 \%$ si la encontró. En la mayoría de los estudios se asocia fuertemente las características sociodemográficas del niño a salud oral. Además, en el $17 \%$ de ellos se postulan otras relaciones con la caries infantil que incluyen tipo de diente, sexo o religión.

Conclusión: La evidencia recabada en este estudio no relaciona concluyentemente la caries y obesidad infantil. A pesar de que las herramientas de medición fueron las mismas, los resultados fueron variados. Esto podría deberse a la zona geográfica o a otras variables intervinientes como el nivel sociodemográfico, socioeconómico, o nivel educacional parental.

\section{Capsazepina y su uso en cáncer oral}

Alvarez, Sebastián' ${ }^{1}$ Cubillos, Tamara' ${ }^{1}$, Muñoz, Francisca', Cortés, Rubén ${ }^{2}$, Osorio, Rodrigo ${ }^{3}$

'Estudiante Pregrado, Facultad de Odontología, Universidad de Chile. 2Departamento de Pregrado, Facultad de Odontología, Universidad de Chile. 3Departamento de Odontología Restauradora, Facultad de Odontología, Universidad de Chile.

Introducción: Se ha documentado ampliamente los beneficios que presenta la capsaicina en la terapia del cáncer, esta molécula es la que otorga el característico picor a los pimientos del género Capsicum, a través de la activación del receptor TRPV-1. Para obtener estos beneficios sin la acción del canal se ha investigado una alternativa, la capsazepina, que es un análogo sintético de la capsaicina antagonista de TRPV-1.

El objetivo de esta investigación fue revisar la literatura disponible para conocer los efectos de la capsazepina en cáncer oral.

Metodología: Se realizó una revisión sistemática en la base de datos Pubmed, utilizando los términos "capsazepine AND oral cancer".
Se obtuvo en total ocho artículos, se estableció como criterio de inclusión el uso terapéutico de capsazepina o sus análogos en el tratamiento de cáncer.

Resultados: Cinco artículos fueron considerados, tres fueron descartados por no cumplir con el criterio de inclusión.

Discusión: Se demuestra un efecto citotóxico mayor de la capsazepina y sus análogos en comparación a capsaicina, además de ser independiente de la activación de TRPV-1. Se plantea como mecanismo de acción el aumento de especies reactivas a oxígeno, creando un ciclo de disfunción mitocondrial. Además, la capsazepina inhibió la hiperalgesia térmica inducida por la inoculación de células tumorales.

Las principales limitaciones fueron que los estudios siguen una misma línea investigativa y basan sus conclusiones en sus mismos estudios, la escasa cantidad además que todos se basan en estudios en animales de experimentación.

Conclusión: La capsazepina parece ser una molécula prometedora en el tratamiento de cáncer, ya que presenta un efecto mayor que no depende de la activación de TRPV-1. Sin embargo, se recomienda realizar más investigaciones de tipo in vivo en relación a cáncer oral, para luego realizar ensayos clínicos que aclaren la eficacia de la molécula en humanos.

\section{Colutorios antisépticos alternativos al uso de povidona iodada (PVP-I) en tiempos de pandemia. Revisión bibliográfica}

Autores: Del Río, S'1, López, G1; Medina, J', Ortega, M'; Silva, C'1, Uribe, $\mathrm{V}^{1}$, Vargas, $\mathrm{F}^{1}$, Betancur, $\mathrm{D}^{2}$

'Estudiante de pregrado, Facultad de Odontología, Universidad de Concepción. 2Departamento de Estomatología Quirúrgica, Facultad de Odontología, Universidad de Concepción.

Introducción: La liberación de gotas/aerosoles durante procedimientos odontológicos, resultan ser maniobras de alto riesgo de transmisión de SARS-CoV-2 desde la boca, la que actúa como reservorio de partículas virales, recomendándose utilizar colutorios antisépticos previo a intervenciones.

Objetivos: Comparar la eficacia de antisépticos (clorhexidina, $\mathrm{H}_{2} \mathrm{O}_{2}$ y cloruro de cetilpiridino) como alternativa a PVP-I reduciendo la carga de SARS-CoV-2, previo a la atención dental.

Hipótesis: Los colutorios antisépticos clorhexidina ( $\mathrm{CHX}), \mathrm{H}_{2} \mathrm{O}_{2}$ y cloruro de cetilpiridino (CCP) pueden emplearse como alternativa a PVP-I, reduciendo la carga de Sars-Cov-2 en saliva. 
Materiales y Métodos: Búsqueda narrativa en PubMed, Web of Science y Scopus, mediante los términos "Antiseptic", "Cetylperydinium chloride", "Chlorexidine", "Coronavirus", "Covid-19", "Dentistry", "Hydrogen peroxide", "Pandemic", "SARSCoV-2", usando operadores booleanos "AND" $y$ "OR" e incluyendo artículos en inglés entre 2020-2021.

Resultados: 255 artículos encontrados se filtraron por título, de estos, 25 fueron analizados a texto completo para extraer datos.

Conclusión: La Asociación Dental Americana recomienda PVP-I al $0.2 \%$ para disminuir la transmisión de SARS-CoV-2, produciendo pigmentaciones en restauraciones/dientes; contraindicándose en embarazadas, enfermos renales, paciente con tiroiditis activa o tratados con yodo radioactivo; siendo alternativas la $\mathrm{CHX}, \mathrm{H}_{2} \mathrm{O}_{2}$ y CCP.

CCP inactiva SARS-CoV-2 al 0.0125-0.3\%, reduciendo sostenidamente la carga viral salival. CHX al 0,12\% mostró In vitro un efecto inactivante insuficiente; mientras que al 0,2\% la evidencia es contrastante con respecto a su eficacia. A nivel in vivo, su uso al 0,12\% disminuyó transitoriamente la carga viral con una sustantividad de 2 horas. $\mathrm{H}_{2} \mathrm{O}_{2}$ al 0,5\% asegura actividad virucida con baja sustantividad pudiendo inactivarse por efecto bacteriano y/o enzimático del hospedero, pero falta evidencia demostrando eficacia disminuyendo carga salival de SARS-CoV-2. Esto muestra que los colutorios antisépticos podrían reducir la transmisión de SARS-CoV-2 en procedimientos dentales. Mas, apremia mayor evidencia que los compare.

\section{Comparación del tratamiento ortodóncico realizado con alineadores transparentes versus aparatología fija: Una revisión bibliográfica}

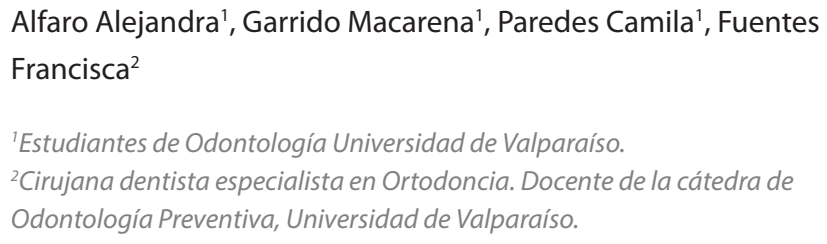

Alfaro Alejandra', Garrido Macarena', Paredes Camila', Fuentes Francisca ${ }^{2}$

'Estudiantes de Odontología Universidad de Valparaíso. ${ }^{2}$ Cirujana dentista especialista en Ortodoncia. Docente de la cátedra de Odontología Preventiva, Universidad de Valparaíso.

Introducción: El tratamiento de ortodoncia tiene como objetivos devolver la estética, la estabilidad funcional y la armonía estructural. Durante los últimos años, la exigencia de tratamientos estéticos ha impulsado la implementación de alineadores transparentes. Sin embargo, no se tiene información clara sobre las diferencias entre los distintos tipos de aparatología ortodóncica, surgiendo la pregunta ¿Existe diferencias entre el tratamiento ortodóncico realizado con alineadores transparentes y aparatología fija, según la literatura científica?
Objetivo: Comparar el uso de alineadores transparentes como tratamiento ortodóncico en relación a tratamiento de aparatología fija.

Metodología: Se realizó una revisión sistemática de la literatura científica usando las bases de datos PubMed, Scopus y Scielo en Abril de 2021, utilizando entre las palabras claves "dental aligners", "clear aligner", "orthodontics", "orthodontic treatment", "effectiveness", "indications". Se incluyeron investigaciones experimentales y observacionales realizadas en humanos con dentición definitiva, que comparaban la aparatología fija y alineadores transparentes como tratamiento ortodóncico, con máximo 5 años de antigüedad y en cualquier idioma. Se excluyeron artículos que realizaron intervenciones en pacientes clases II o III esqueletal y aquellos no encontrados como texto completo. La selección de artículos fue realizada por tres autores de manera independiente.

Resultados: Se obtuvo un total de 1880 artículos, de los cuales tras la eliminación de duplicados (113 publicaciones) y aplicar criterios de elegibilidad establecidos quedaron finalmente 17 artículos seleccionados en la investigación.

Conclusión: Al comparar ambas técnicas ortodóncicas se observaron resultados similares en cuanto a la salud periodontal y movimientos dentarios en pacientes clase I. Sin embargo, la aparatología fija tiene ventajas en cuanto al costo y versatilidad del tratamiento, mientras que los alineadores transparentes presentan menor impacto en la calidad de vida de los pacientes, duración de tratamiento y reabsorción radicular, resultando ser una buena opción de tratamiento en casos de apiñamiento leve según la literatura científica.

\section{Complicaciones a nivel oral en pacientes con antecedentes de quemaduras orofaciales graves}

Oscar Rodríguez ${ }^{1}$, Valeria Castro ${ }^{1}$, Verónica Aravena²

'Estudiante de Odontología Universidad San Sebastián, Sede Valdivia. ${ }^{2}$ Cirujano Dentista, Magister en Educación Universitaria para Ciencias de la Salud, Docente Universidad San Sebastián, Sede Valdivia.

Introducción: Las quemaduras corresponden a un problema de salud pública que pueden provocar múltiples repercusiones en la víctima, tanto a nivel local como sistémico. En la región orofacial tienen alto impacto en las estructuras, morfología, función y estética del paciente, siendo capaces de generar problemas de sensibilidad, alimentación, fonación, higiene oral, e incluso, en la calidad de vida psicosocial. El objetivo de la presente revisión es identificar las principales complicaciones a nivel oral en pacientes con antecedente de quemaduras graves. 
Metodología: Se realizó una revisión sistemática de artículos publicados en revistas científicas y bases de datos como Pubmed y EBSCO. Los criterios de selección incluyeron revisiones narrativas, estudios transversales y casos clínicos publicados en los últimos 15 años.

Resultados: De los 15 artículos encontrados, 10 cumplían con los criterios de selección, los cuales mencionan complicaciones a nivel oral en pacientes con quemaduras graves, producidas posteriormente en un tiempo de moderado a largo plazo. Se destaca que estos pacientes presentan mayor riesgo de caries y enfermedad periodontal, cuya severidad es directamente proporcional con el grado de la quemadura y el tiempo trascurrido del incidente. Por otro lado, debido a la cicatrización, se produce contracción del tejido de granulación, lo que puede provocar microstomía y se reporta un caso de fibrosis de tejidos blandos en la mejilla, calcificada con el tiempo y de radiopacidad similar al hueso; y 2 casos de autoextracción de dientes en niños, que podrían estar relacionadas al dolor crónico posterior a la quemadura.

Conclusión: Las quemaduras orofaciales son un tipo de accidente frecuente, por lo que, para poder planificar un plan de tratamiento integral, es necesario saber cómo abordarlas. Actualmente faltan estudios con mejor evidencia científica, que indiquen las complicaciones que pueden presentar estos pacientes, los factores que influyen en su desarrollo y su forma de atención.

\section{Consideraciones del rol del odontólogo en el manejo de un paciente con cáncer oral}

\author{
Catalina Paz' ${ }^{1}$ Javiera Verdugo' ${ }^{1}$, Verónica Palacios ${ }^{1}$ \\ Pontificia Universidad Católica de Chile
}

Introducción: El cáncer oral (CO) se diagnostica generalmente en etapas tardías, como una úlcera que no repara o con dolor refractario. Se sabe que está asociado con morbilidad social y psicológica que conduce a una mala calidad de vida. El objetivo de esta revisión bibliográfica narrativa fue identificar las intervenciones que debería realizar el odontólogo antes, durante y después de la terapia contra el CO, para prevenir y manejar efectos adversos de esta.

Métodos: La búsqueda, realizada en septiembre de 2020, incluyó artículos desde el 2015, en idioma inglés, español y chino. Se utilizó PubMed y Tripdatabase, empleando los términos "mouth neoplasm", "palliative care", "quality of life" and "oral health chemotherapy".

Resultados: Se encontraron 733 estudios; después de analizar títulos, resúmenes y excluir duplicados y su lectura completa, se incluyeron 17 artículos.
Discusión: El tratamiento odontológico se debe realizar antes de iniciar la terapia oncológica, eliminando focos infecciosos con exodoncias de dientes con lesiones cariosas avanzadas, patologías periapicales e infecciones periodontales porque pueden ser complicaciones durante o después del tratamiento. Se recomienda un enfoque menos conservador en quienes presentan mala salud oral e higiene deficiente y aplicar acciones preventivas como uso de clorhexidina, flúor, estimulación del flujo salival y educación de higiene oral.

Durante la radioterapia se recomienda láser de baja frecuencia y crioterapia para la prevención y tratamiento de la mucositis. Después el paciente debe tener un control clínico e imagenológico riguroso. Se sugiere, minimizar la radiación sobre glándulas salivales. Para alivio de la hiposalivación se recomienda pilocarpina, goma de mascar sin azúcar o sustitutos de saliva.

Conclusión: La terapia odontológica en pacientes con CO es de suma importancia antes, durante y después del tratamiento. Si bien existen protocolos, los criterios terapéuticos dependen del juicio clínico y la experiencia del odontólogo, teniendo siempre un enfoque multidisciplinario.

\section{Cúrcuma como tratamiento alternativo de liquen plano oral. Revisión Bibliográfica}

\author{
Carolina Cabezas Fierro', Belén Hernández Muñoz², Marcelo \\ Sánchez Astorga ${ }^{3}$ \\ 'Universidad de Talca, Facultad Ciencias de la Salud, Escuela de Odontología, \\ Alumna Pregrado. \\ ${ }^{2}$ Departamento de Departamento de Estomatología \\ ${ }^{3}$ Docente de Patología y Diagnóstico Oral.
}

Introducción: El liquen plano oral (LPO) es una enfermedad inflamatoria crónica mucocutánea y de etiología desconocida. Los corticosteroides son utilizados como tratamiento convencional, empleándose por largos períodos dada la cronicidad de la enfermedad e inclusive en altas dosis.

Las terapias alternativas han cobrado interés debido a la alta prevalencia de la patología y los efectos secundarios de los esteroides, es así como la cúrcuma, un producto natural y no tóxico, además de sus efectos antiinflamatorios ha despertado interés como tratamiento para el LPO.

Objetivo: Describir los efectos del uso de cúrcuma como tratamiento alternativo en el liquen plano oral.

Métodos: Efectuamos una búsqueda avanzada en las bases de datos Pubmed, Scopus, Web of Science y Scielo. Realizamos la estrategia de búsqueda: "Lichen Planus, Oral" AND "Curcumin". 
Incluimos estudios publicados desde 01-01-2016 hasta 16-04-2021, en idioma inglés-español y en humanos. Excluimos los artículos que no utilizaban la cúrcuma como tratamiento para el LPO.

Resultados: Obtuvimos 41 artículos, eliminamos los duplicados y seleccionamos según título, resumen y texto completo, incluyendo 12 artículos, ya que cumplieron con nuestros criterios de elegibilidad.

Discusión: El uso prolongado de corticoesteroides produce efectos secundarios como supresión suprarrenal y candidiasis secundaria. A diferencia de esto, la evidencia describe que el uso de cúrcuma no posee efectos nocivos, además de propiedades antioxidantes, antiinflamatorias y anticancerígenas. La evidencia científica describe que ambos tratamientos resuelven la lesión, ya que en ambas se registraron mejorías significativas, la importancia radica en que, la cúrcuma no provoca efectos secundarios.

Conclusión: La evidencia científica demuestra que la utilización de cúrcuma como tratamiento alternativo para liquen plano oral, logra efectos y resultados exitosos, aun así, los autores sugieren más estudios para ajuste de dosis y tiempo de exposición.

\section{Efectividad de laserterapia versus corticoides tópicos en estomatitis aftosa recurrente: Una revisión bibliográfica}

Samuel Cáceres ${ }^{1}$, Rolfi Richards ${ }^{1}$, Camila Paredes ${ }^{1}$, Rodrigo Fuentes ${ }^{1}$

'Facultad de Odontología, Universidad de Valparaíso.

Introducción: La estomatitis aftosa recurrente (EAR) es una enfermedad inflamatoria crónica que afecta principalmente a la mucosa oral no queratinizada. Debido a su naturaleza idiopática aún no se ha establecido un tratamiento curativo. Las terapias existentes se enfocan en aliviar la sintomatología, acelerar la cicatrización, reducir la gravedad de los episodios y disminuir la frecuencia de recurrencia, sin embargo, no se ha determinado cuál es el tratamiento más efectivo. El objetivo de esta revisión sistemática fue comparar la eficacia, entre la terapia convencional de corticoides tópicos y la laserterapia, en la disminución de la sintomatología y tiempo de curación de la EAR.

Metodología: Se utilizaron las bases de datos Scopus, PubMed, Cochrane Library, Web of Science. Se incluyeron ensayos clínicos publicados desde el 2010 a 2021, en cualquier idioma y que evaluaran el tratamiento de corticoides tópicos versus el láser en humanos. Se excluyeron aquellos estudios que intervinieron pacientes con condiciones sistémicas y/o que estaban bajo tratamiento farmacológico. Tres investigadores realizaron la evaluación de calidad con las herramientas de RoB-2 y ROBINS-I, de forma independiente.
Resultados: Las búsquedas registraron 3.392 artículos. Luego de eliminar los duplicados y los estudios que no cumplían con los criterios de elegibilidad, quedaron 8 artículos para su revisión en texto completo, pero sólo 4 fueron seleccionados. Finalmente, 3 artículos fueron incluidos en la presente revisión sistemática tras la evaluación del riesgo de sesgo.

Conclusiones: De los estudios incluidos, sólo uno tiene riesgo de sesgo moderado, mientras que otros dos estudios tienen un bajo riesgo de sesgo. En base a estos se concluye que existe una disminución significativa del dolor luego de la primera sesión de laserterapia y no existen mayores diferencias respecto al tiempo de curación entre ambos tratamientos.

\section{Enfermedades profesionales en la práctica profesional odontológica}

\author{
D. Marinkovic ${ }^{1}$, D. Azócar ${ }^{1}$, V. Fuentes ${ }^{1}$, R. Von Kretschmann \\ 'Escuela de Odontología, Facultad de Medicina, Pontificia Universidad \\ Católica de Chile. \\ 2Escuela de Odontología, Facultad de Medicina, Pontificia Universidad \\ Católica de Chile.
}

Introducción: Una enfermedad profesional (EP) es aquella causada de manera directa por el ejercicio de la profesión que realice una persona y que le produzca daño, incapacidad o muerte. Se ha reportado que los odontólogos son propensos a desarrollar patologías relacionadas con su ejercicio profesional, exponiéndose a riesgos de naturaleza física, biológica, química y psicosocial. Los objetivos de esta revisión narrativa son determinar las enfermedades profesionales odontológicas más reportadas en la literatura, sus etiologías y principales consecuencias.

Métodos: Se utilizaron herramientas de búsqueda en PubMed, EBSCO, Epistemonikos y ScienceDirect con criterios de inclusión y exclusión, tales como año de publicación, idioma y accesibilidad.

Resultados: Se encontraron 1970 resultados, de los cuales se seleccionaron 54 artículos utilizando los criterios de inclusión y exclusión previamente establecidos.

Discusión: La EP asociada a la práctica odontológica más reportada en la literatura fueron los trastornos musculoesqueléticos, asociados a ergonomía deficiente en la práctica clínica. Además, se reportó la afección auditiva por tinnitus y disminución de la capacidad auditiva. Se reportaron también, trastornos pulmonares como fibrosis pulmonar idiopática, hipersensibilidad a biomateriales odontológicos y riesgo de enfermedad por mayor exposición a virus respiratorios. Por último, se describieron otras enfermedades menos prevalentes como Síndrome del túnel carpiano, estrés y Síndrome de Burnout. 
Conclusión: Es muy importante que los dentistas tengan conocimiento actualizado de estas enfermedades profesionales, reconociendo los factores de riesgo y manteniendo las condiciones de trabajo adecuadas para adoptar medidas preventivas. Si bien, este estudio estableció aquellas EP más reportadas, faltan otros estudios que determinen su prevalencia a nivel nacional y mundial.

\section{Estrategias de comunicación en salud y su impacto en cambios conductuales de personas mayores}

\author{
Isidora Neira', Daniel Carreño², Rodrigo Oporto', Agustina \\ Maass ${ }^{1}$, Fernanda Naser ${ }^{1}$, Francisca Muñoz ${ }^{1}$ \\ 'Internos de odontología de la Pontificia Universidad Católica de Chile. \\ ${ }^{2}$ Profesor Asistente Adjunto en la Pontificia Universidad Católica de Chile.
}

Introducción: En salud, gran parte del éxito de los tratamientos depende de la comunicación que se establece con el paciente. Muchos mensajes buscan informar y educar para así promover un comportamiento específico. Estos, pueden tener una connotación positiva o negativa, aún buscando un mismo objetivo. Estudios han indicado que la connotación del mensaje determina su efectividad y esta diferencia se ha observado de manera más acentuada en personas mayores. El objetivo de este trabajo es estudiar qué tipo de mensaje es más efectivo para lograr un cambio conductual en adultos mayores.

Materiales y métodos: Se realizó una revisión narrativa. La búsqueda, realizada en abril de 2021, no limitó fecha de publicación, sólo se incluyeron estudios referidos a adultos mayores, en inglés. Se utilizó la base de datos PubMed, empleando los términos "aging", "promotion", "positive message" y "negative message".

Resultados: Se encontraron 17 artículos; después de analizar títulos y resúmenes, se seleccionaron 8 artículos. Luego de su lectura completa, se incluyeron 5 artículos.

Discusión: Según la literatura, los mensajes con enfoque positivo resultaron más efectivos a la hora de generar un cambio de conducta en adultos mayores, en comparación a los negativos. Estos tienen beneficios tales como que se recuerdan más fácilmente, se entienden mejor, se observa mayor interés y motivan más al paciente. Un ejemplo de mensaje positivo es "Mientras más temprano se diagnostique su enfermedad, más posibilidades tendrá de recuperarse"; en cambio, un mensaje con connotación negativa sería "Mientras más tarde se diagnostica, menos posibilidades tendrá de recuperarse".
Conclusión: El éxito de los tratamientos en odontología depende en gran parte del cambio conductual que realice el paciente. Resulta fundamental la forma en que se transmite el mensaje y su internalización. Los estudios son escasos y no se encontraron resultados específicos sobre salud oral.

\section{Flujo Salival y Caries Dental Post- Radioterapia en Pacientes con Cáncer de Cabeza y Cuello}

\author{
Carla Alarcón C. 'Pablo Fuentes D. ' , Catalina Guerra P. ${ }^{1}$, Issis \\ Luque $\mathrm{M}^{2}$ \\ ${ }^{1}$ Estudiante de pregrado Facultad de odontología Universidad de Valparaíso \\ ${ }^{2}$ Profesor adjunto Universidad de Valparaíso
}

Objetivo: Evaluar a través de una revisión sistemática de la literatura, la asociación entre alteraciones del flujo salival y la aparición de lesiones de caries posterior a la radioterapia en pacientes con cáncer de cabeza y cuello.

Materiales y Métodos: Se realizó una revisión sistemática de la literatura disponible en las bases de datos de PubMed, Scopus, Proquest, Web of Science, Lilacs y Google Scholar considerando como último ingreso el día 4 de Diciembre 2020. Se filtraron las publicaciones según título, resumen y criterios de elegibilidad, luego se realizó un análisis de calidad de forma individual y grupal, para posteriormente realizar un análisis estadístico tipo metaanálisis.

Resultados: Se incluyeron 19 estudios: 6 ECAs, 6 cohortes, 4 series de casos, 1 estudio clínico transversal, 1 revisión sistemática y 1 casos y controles. A partir del análisis cualitativo los estudios de alta calidad, fueron Hey J. (ECAs), Almstahi A. (cohorte), Beer K. (cohorte) y Escoda J. (serie de casos).

Conclusión: Existe una relación positiva entre la presencia de caries dental y alteraciones del flujo salival posterior a radioterapia en pacientes con cáncer de cabeza y cuello, pero es necesario contar con nuevos estudios centrados en el análisis de calidad salival para confirmar su importancia.

Relevancia clínica: Cobra importancia la motivación, instrucción en higiene bucal y cambios en hábitos alimenticios de los pacientes, además de citas regulares durante y después del tratamiento oncológico, logrando prevenir la aparición de caries post-radioterapia y minimizar el riesgo de osteorradionecrosis, mejorando así su calidad de vida. 


\section{Inequidad de género en el acceso a la atención odontológica en Chile}

\author{
Araya Paula', Soto Savka', Flaig Karen ${ }^{1}$, Crisosto Claudia ${ }^{2}$ \\ 'Universidad San Sebastián, Facultad de Odontología, Estudiante de \\ Pregrado $5^{\circ}$ año. \\ Cirujano Dentista, Magíster (C) Salud Pública, Especialista en Periodoncia e \\ implantología, Docente Pregrado Universidad San Sebastián.
}

Introducción: Equidad en salud involucra que todos tengan oportunidad justa al acceso. Chile, ha puesto énfasis en el enfoque de género y equidad, elaborando programas para mujeres de grupos vulnerables, como "Más Sonrisas para Chile" y "GES embarazada". No obstante, se observan desigualdades en indicadores de salud oral en distintos sectores de la población.Esta revisión bibliográfica tiene por objetivo establecer inequidades de género en acceso a salud oral según diferentes determinantes.

Material y método: Se realizó una búsqueda bibliográfica en Pubmed/Medline entre 2015-2020. Texto completo. Palabras claves: "Oral health inequality" "Female" "Public Health". Se utilizaron recursos bibliográficos MINSAL y Scielo.

Resultados: Se describe una gradiente socioeconómica y educacional para patologías bucodentarias, que aumenta al considerar género, ya que las mujeres debido al desarrollo del mercado y costo de vida, acrecientan su carga laboral, empleos de menor remuneración (-29,3\%), en ocasiones inestables y sin cobertura de salud, generando una profunda inequidad; especialmente, en aquellas de bajos recursos, que limitan su atención a consultas de urgencia por la nula posibilidad a atención de altos costos. Algunos estudios y encuestas nacionales, indican que las mujeres presentan mayor severidad de caries, mayor dentición no funcional y uso de prótesis, con importante participación de determinantes socioeconómicos, que marcan las diferencias de género.

Discusión: Existen escasos estudios epidemiológicos nacionales que reflejen resultados de programas gubernamentales bajo una perspectiva de género.

Factores socioeconómicos y educacionales son decisivos en el acceso a atención dental, pese a programas odontológicos que intentan equiparar las brechas sociales en salud oral.

Conclusiones: Problemas de inequidad en acceso a atención, como diferencias en salud según género, resultan de vital importancia para elaborar políticas de salud bucal basadas en determinantes sociales, que permitan disminuir la espera por atención odontológica, el impacto en la salud general, autoestima, inclusión y rol social de las personas.

\section{Inequidades en salud oral en Chile, ¿Son suficientes medidas implementadas?}

\author{
Belmar Andrea', Loyola Isabel', Paci Benjamín', San Martín \\ Fernanda', Santibáñez Maria', Suárez Sofia' ${ }^{1}$, Mellado Beatriz² \\ 'Escuela de Odontología, Facultad de Medicina, Pontificia Universidad \\ Católica de Chile. Santiago, Chile. \\ 2Escuela de Odontología, Facultad de Medicina, Pontificia Universidad \\ Católica de Chile
}

La salud está establecida como un derecho para toda la población, pero distintos estudios y encuestas realizadas han demostrado que no todos los individuos tienen el mismo acceso a una salud de calidad. En cuanto a salud bucal, se observa que esta inequidad se acentúa aún más, y se ha visto que los determinantes sociales que están implicados en esta desigualdad son la brecha socioeconómica existente entre las diferentes clases sociales y el nivel de educación que adquieren las personas según sus oportunidades. Para establecer la salud oral como un derecho y no como un privilegio el estado chileno ha implementado medidas como las garantías explicativas en salud, también llamado GES, el cual incluye 5 patologías orales que buscan mejorar la salud bucal de la población. Otra de las medidas que han contribuido a mejorar la salud oral en Chile, fue un programa de fluoración de sal a nivel comunitario y otro a nivel individual mediante el uso de flúor tópico en gel. El objetivo de esta revisión narrativa es establecer las medidas que ha implementado el estado chileno para reducir las inequidades existentes en la salud oral de la población chilena y analizar si estas han sido suficientes. Actualmente, producto de la pandemia COVID-19 las inequidades respecto a salud oral se han visto aumentadas, puesto que se restringieron las atenciones odontológicas electivas, de las 5 patologías GES sólo se están implementando 2 de ellas, dejando a una buena parte de la población sin atención. Finalmente, es importante destacar que sería recomendable realizar un estudio más actual que evalúe específicamente la inequidad en salud oral en Chile posterior a la pandemia, para implementar nuevas medidas que tomen en cuenta las determinantes sociales que demarcan esta inequidad en salud oral de calidad.

\section{Obesidad y periodontitis, ¿cuál es su verdadera asociación?, revisión bibliográfica}

\author{
Escarate, Francisca' ${ }^{\text {, Caracci, Ginnia }}{ }^{1}$, Oyarzo, Natacha² \\ 'Estudiante de Pregrado, Escuela de Odontología, Facultad de Medicina, \\ Pontificia Universidad Católica de Chile. \\ 2Escuela de Odontología, Facultad de Medicina, Pontificia Universidad \\ Católica de Chile.
}


Introducción: Obesidad y periodontitis son 2 enfermedades inflamatorias crónicas no transmisibles comunes. Al 2030 más del $20 \%$ de la población mundial será obeso. Estudios evidencian el posible rol de la obesidad en el inicio y progresión de periodontitis. Parámetros como IMC, porcentaje de grasa corporal y circunferencia de cintura, tendrían impacto negativo en la Periodontitis.

Objetivos: El objetivo de este estudio es revisar la información de la literatura disponible sobre los conocimientos actualizados de enfermedad periodontal y su relación con obesidad determinando si la obesidad es un posible factor de riesgo para enfermedad periodontal.

Metodología: Se realizó una revisión narrativa con artículos científicos de 3 bases de datos, PubMed, Scopus y Cochrane Library. Los términos utilizados fueron "obesity" AND "periodontal disease" AND "systemic inflammation". Incluyendo todos los artículos publicados en los últimos 5 años, idioma inglés o español. De 61 artículos encontrados, 24 fueron escogidos. Se elaboró un diagrama de flujo PRISMA que muestra identificación, selección, elegibilidad y estudios incluidos.

Resultados: De los artículos se encontró: El mecanismo por el cual la obesidad podría afectar la salud periodontal es aún incierto. Se sabe que obesidad y periodontitis comparten a las adipocinas TNF-alfa e IL-6 en la fisiopatología de cada una de ellas. El aumento de adipocinas en pacientes obesos genera una sobreproducción de ROS, y un estado proinflamatorio provocado por el estrés oxidativo producto de la obesidad que podría impactar en una mayor susceptibilidad a las infecciones bacterianas como la periodontitis. Se observó que en pacientes obesos las bacterias del complejo rojo de Socransky se encuentran en mayor proporción que en pacientes no obesos.

Discusión y Conclusión: Hay evidencia que sugiere que la obesidad esta asociada con la periodontitis pero aún faltan estudios que expliquen los mecanismos y vías fisiopatológicas que den respuesta a la plausibilidad biológica de esta relación.

\section{Participación de la Vía Sonic Hedgehog en displasia epitelial oral}

Patricio Miranda, Paula Rojas ${ }^{1}$, Daniela Adorno ${ }^{2}$

'Estudiante de Pregrado, Facultad de Odontología, Universidad de Chile. ${ }^{2}$ Departamento de Medicina y Patología Oral, Facultad de Odontología, Universidad de Chile.

La vía de señalización Hedgehog, participa en desarrollo embrionario y regeneración tisular. La displasia epitelial oral es un espectro de cambios arquitectónicos y citológicos epiteliales descrito en lesiones orales premalignas, está asociada a mayor riesgo de progresión a Carcinoma oral de células escamosas. La evidencia ha reportado que desregulaciones en la vía SHH están involucradas en la proliferación y comportamiento invasivo de carcinomas, pero su implicancia en la patogénesis en displasia epitelial oral aún no está bien estudiada.

El objetivo de esta revisión bibliográfica es determinar la participación de la vía Sonic Hedgehog en displasia epitelial oral, para ello se realizó una búsqueda en las bases de datos PUBMED, Scielo y LILACS, utilizando las palabras claves'Hedgehog pathway AND oral epithelial dysplasia'. Se incluyeron estudios en idioma inglés, y se excluyeron aquellos no atingentes al objetivo de estudio. Se encontraron 6 artículos, 3 cumplieron los criterios de inclusión. Todos recomiendan mayor investigación para entender el rol de $\mathrm{SHH}$ en displasia, y reportan una mayor expresión de las proteínas de la vía comparado con mucosa normal, además de sugerir participación en la patogénesis.

Está reportado que las proteínas de la vía SHH tienen una importante participación en invasión y proliferación de COCE, pero en relación a displasia aún no está bien comprendido. Los estudios muestran una mayor expresión en displasia epitelial oral y lesiones orales premalignas. Se debe investigar mayormente para comprender su participación en displasia epitelial oral, debido a la importancia que podría tener a nivel clínico como terapéutico, ya que, una mayor expresión de la vía tanto en displasia como en carcinoma oral sugieren que puede ser un nuevo blanco terapéutico, como también puede ser un biomarcador de pronóstico de enfermedad o factor predictor para estadios futuros de cáncer.

\section{Profesionalismo y el uso de redes sociales en odontología}

\author{
Gabriela Salinas ${ }^{1}$, Dr. Uriel Montenegro \\ 'Escuela de Odontología, Pontificia Universidad Católica de Chile
}

Introducción: En los últimos 10 años el uso de redes sociales ha aumentado de forma exponencial, y en el ámbito odontológico su uso ha transformado la relación odontólogo-paciente. Un mal uso de redes sociales, como la divulgación de información sensible, repercute en esta relación causando problemas de diversa índole y afectando a la salud pública y conocimiento general.

Material y Métodos: se realizó una revisión narrativa, utilizando las bases de datos: PubMed, ProQuest Central, Dentistry and Oral Science Source y Medline realizando la búsqueda con los términos claves "dentistry"'"professionalism"y"social media". Posteriormente se analizaron los datos y resultados. Se utilizaron artículos en inglés y español, publicados con fecha 2011 y posterior. 
Resultados: Se encontraron 47 artículos, que se filtraron según atingencia al tema y se seleccionaron 18, que estaban enfocados en el impacto de las redes sociales en el profesionalismo de odontólogos y alumnos de pregrado de odontología. El uso inadecuado de redes sociales repercute en el profesionalismo, y esto se sustenta en 6 aspectos fundamentales como es la ambigüedad del concepto de profesionalismo, manejo inadecuado de las expectativas del paciente, falta de confidencialidad de la información otorgada durante la atención en salud, impacto en la confianza existente en la relación odontólogo-paciente, publicidad y mercantilización de la odontología, educación.

Conclusiones: El uso de redes sociales en odontología conlleva riesgos que pueden alterar la relación odontólogo-paciente, afectando la percepción de profesionalismo por la falta de atención a preceptos éticos y legales que son parte tanto de la comunicación presencial como digital. Es necesario educar a los alumnos de odontología sobre los beneficios y riesgos potenciales del uso de redes sociales en el contexto de la práctica odontológica. Faltan estudios que muestren la realidad nacional y sudamericana respecto al uso de redes sociales y su impacto en odontología.

\section{Pulpotomía parcial en dientes permanentes inmaduros con caries profunda: MTA comparado con hidróxido de calcio}

Valentina Núñez Aravena', Javiera Reyes Velásquez', Andrea Cárdenas ${ }^{1}$

'Escuela de Odontología, Facultad de Medicina, Pontificia Universidad Católica de Chile, Santiago, Chile.

Introducción: La pulpotomía parcial se utiliza para el tratamiento de caries con exposición pulpar en dientes permanentes inmaduros. El agregado de trióxido mineral (MTA) ha sido propuesto como uno de los biomateriales de elección para el tratamiento, pero existe incertidumbre en relación a su efectividad comparado con la del hidróxido de calcio.

Métodos: Realizamos una búsqueda en Epistemonikos, la mayor base de datos de revisiones sistemáticas en salud, la cual es mantenida mediante el cribado de múltiples fuentes de información, incluyendo MEDLINE, EMBASE, Cochrane, entre otras. Extrajimos los datos desde las revisiones identificadas, analizamos los datos de los estudios primarios, realizamos un metanálisis y preparamos una tabla de resumen de los resultados utilizando el método GRADE.
Resultados y conclusiones: Encontramos cinco revisiones sistemáticas, que incluyeron tres estudios primarios, de los cuales todos corresponden a ensayos aleatorizados. Concluimos que la pulpotomía parcial con agregado de trióxido mineral (MTA) podría resultar en poca o nula diferencia en la tasa de éxito comparado a la pulpotomía parcial con hidróxido de calcio, pero la certeza de la evidencia es baja.

\section{Rehabilitación Oral en Pacientes Diagnosticados con Dentinogénesis Imperfecta: Revisión Sistemática de Casos Clínicos}

Daniela Palacio Vivanco', Maria Luisa Redondo Rico', Samantha Molina Perez ${ }^{1}$, Fraider Gutiérrez Meza', Ana Leonor Herrera Gomez ${ }^{1}$, Cristhian Camilo Madrid Troconis²

1Estudiante de pregrado. Facultad de Odontología de la Universidad de Cartagena, Cartagena de Indias, Colombia.

${ }^{2}$ Docente del Departamento de Rehabilitación Oral. Facultad de Odontología de la Universidad de Cartagena, Cartagena de Indias, Colombia.

Objetivo: Analizar los casos clínicos sobre la rehabilitación oral en pacientes diagnosticados con dentinogénesis imperfecta (DI).

Métodos: Se siguieron las pautas de la guía PRISMA. Se realizaron búsquedas en Pubmed, EbscoHost, SciElo y Google Scholar, usando términos como "dentinogenesis imperfecta" AND "case report" OR "clinical case". Dos autores previamente estandarizados realizaron la extracción y tabulación de los datos en Microsoft Excel, se evaluó la calidad metodológica utilizando un instrumento específico de Joanna Briggs Institute (JBI).

Resultados: Se seleccionaron 23 artículos, de los cuales 1 reportaba dos casos clínicos por lo que fueron analizados 24 casos clínicos. Los pacientes eran principalmente de sexo masculino $(n=16)$ entre 1 - 35 años y femenino $(n=8)$ entre 1 - 48 años. El diagnóstico más común fue DI tipo II ( $n=20)$, seguido de DI tipo I $(n=4)$. La mayoría de los casos involucraron sector anterior y posterior $(n=21)$, solo sector posterior $(n=2)$ o anterior $(n=1)$; Las alternativas más frecuentes en el sector anterior fueron: restauraciones indirectas de resina compuesta RIRC ( $n=7)$ con un periodo de seguimiento entre 6 semanas y 13 años; restauraciones directas de resina compuesta $\operatorname{RDRC}(n=7)$ con seguimiento que varió entre 6 semanas y 17 años; coronas de celuloide, $C C(n=3)$ entre 1 a 2 años. En el sector posterior predominaron: coronas de acero inoxidable $\mathrm{CAI}(\mathrm{n}=8)$ con periodo de seguimiento entre 7 meses y 17 años; seguidas de RDRC $(n=7)$ rango de 6 semanas a 17 años y $\operatorname{RIRC}(n=4)$ con rango de 1 a 13 años, mostrando todas un desempeño exitoso. 
Conclusiones: RDRC, RIRC y CAI son ampliamente utilizadas para la rehabilitación oral en pacientes con DI y muestran resultados satisfactorios. Sin embargo, no se pueden generalizar los tratamientos, siendo importante evaluar las condiciones clínicas de cada paciente.

\section{Relación entre consumo frecuente de marihuana y desarrollo de cáncer de cabeza y cuello}

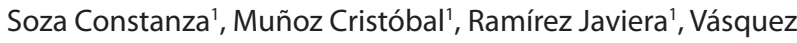 \\ Bárbara', Zárate Eliana', Buitano Hugo' \\ ${ }^{1}$ Facultad de Odontología, Universidad Finis Terrae
}

El cáncer de cabeza y cuello (CCC) es el sexto cáncer más común y comprende diversos tipos de cánceres. La marihuana es la droga ilícita de origen vegetal más consumida y tiene efectos nocivos sobre la región de cabeza y cuello.

Se ha encontrado asociación entre el uso excesivo de marihuana con mayor incidencia de CCC. Sin embargo, siguen existiendo resultados inconclusos en la literatura. El objetivo del trabajo fue determinar si existe asociación entre consumo de marihuana y desarrollo de CCC.

Se realizó una revisión narrativa mediante una búsqueda estructurada en PubMed, EBSCO y Trip. Empleando los términos [Mouth Neoplasms], [Cannabis], [Marijuana smoking] y [Marijuana abuse]. Se aplicaron criterios de Actualidad (2010-2020); Idioma (Inglés-Español); Fumadores frecuentes de marihuana. Se excluyeron textos sobre consumo medicinal de marihuana.

Se encontró un total de 187 documentos. Tras aplicar criterios de inclusión y exclusión, se obtuvieron 23 artículos. Finalmente, tras la eliminación de duplicados y lectura de artículos completos quedó un total de 18 publicaciones.

La combustión de cannabis se describe como posible carcinógeno, pudiendo causar lesiones potencialmente malignas en mucosa oral. Esto se asocia a la presencia de hidrocarburos aromáticos policíclicos, benzopireno y nitrosaminas. Además, Al Bush (2019) señala que fumar un cigarrillo de marihuana equivale a más de 20 de tabaco. Sin embargo, no se ha encontrado relación entre el consumo de marihuana y el desarrollo de CCC. De Carvalho, et al. (2015) no encontraron asociación entre el consumo prolongado de marihuana y el desarrollo de CCC.

En conclusión, la literatura actual disponible presenta datos contradictorios y no concluyentes respecto a la asociación entre el consumo de marihuana y el desarrollo de CCC. Se requiere de más estudios longitudinales y ensayos clínicos aleatorizados con metodologías bien definidas que permitan establecer o descartar una relación causal entre ambos factores.

\section{Relación entre desdentamiento y deterioro cognitivo: Rol de la rehabilitación oral de personas mayores}

\author{
Benjamín Ramos ${ }^{1}$, José Patricio Ponce', Beatriz Mellado² \\ 'Estudiantes de sexto año, Escuela de Odontología UC \\ ${ }^{2}$ Profesor Asistente Adjunto, Escuela de Odontología UC
}

Objetivo: Analizar información disponible relativa a procesos de deterioro cognitivo y su relación con el edentulismo. Asimismo, evidenciar el aporte de la rehabilitación protésica de pacientes geriátricos desdentados en atenuar la progresión del deterioro cognitivo.

Método: Revisión narrativa a partir de la búsqueda bibliográfica en bases de datos de ciencias de la salud como PubMed. Para la búsqueda se emplearon términos Medical Subject Headings (MeSH) "Mastication”, "Cognitive Dysfunction", "Cognitive Impairment", "Cognition Disorders/physiopathology" y "Tooth Loss". Se utilizaron como criterios de inclusión artículos de máximo 10 años de antigüedad e idioma inglés.

Resultados: Se seleccionaron 20 artículos, en los cuales se asocia el desdentamiento con mayor riesgo de desarrollar demencia en pacientes adultos sobre los 70 años. Se observó una asociación positiva entre el número de contactos oclusales de dientes antagonistas y puntajes obtenidos en pruebas de examinación cognitiva. Además, se reporta la existencia de una relación entre función masticatoria y procesos cognitivos, definida como "eje cerebro-estomatognático". Estudios recientes señalan que el uso de prótesis dental ha mostrado incrementar el flujo sanguíneo cerebral y activar la corteza prefrontal, evidenciándose que en adultos de la tercera edad, una mejor habilidad masticatoria está asociada con mejores funciones cerebrales y reducción del riesgo de demencia.

Conclusión: Se sugiere que una óptima función masticatoria resulta un factor protector en pacientes con deterioro cognitivo, debido a su contribución en el flujo sanguíneo cerebral. Además, existe una progresión mayor de deterioro cognitivo en pacientes geriátricos desdentados, comparado con pacientes dentados o rehabilitados. Esto es posible de explicar mediante la intensidad de la función masticatoria otorgada por la presencia de dientes (naturales o artificiales). Sin embargo, la gran mayoría de los estudios disponibles son de carácter transversal y presentan factores confundentes, tales como condiciones nutricionales, físicas, entre otras. Así, se sugiere realizar estudios de carácter longitudinal a futuro. 


\section{Remoción químico-mecánica de caries y resistencia de unión de sistemas adhesivos a dentina: Una revisión sistemática}

Fraider Gutiérrez Meza*1, Samantha Molina Pérez' Daniela Palacio Vivanco', María Luisa Redondo Rico', Ana Leonor Herrera Gómez', Mario Fernando de Goes ${ }^{2}$, Cristhian Camilo Madrid Troconis ${ }^{3}$

'Estudiante de pregrado. Facultad de odontología, universidad de Cartagena, Cartagena, Colombia.

${ }^{2}$ Docente de la Facultad de Odontología de Piracicaba, Universidad Estadual de Campinas, São Paulo, Brasil.

${ }^{3}$ Docente del Departamento de Rehabilitación Oral. Facultad de Odontología de la Universidad de Cartagena, Cartagena de Indias, Colombia.

Objetivo. Analizar la evidencia que compara el impacto de los agentes de remoción químico-mecánica de caries (ARQMC) y técnicas convencionales de remoción en la resistencia de unión (RU) de sistemas adhesivos a dentina.

Métodos. Esta revisión sistemática siguió la guía PRISMA. Se realizaron búsquedas en PubMed/Medline, Scopus y ScienceDirect (última actualización: 5 de abril de 2021) utilizando palabras clave relacionadas. Los resultados de las búsquedas fueron exportados a Rayyan Systems Inc para eliminar duplicados, lectura de resúmenes y clasificación inicial. Se realizaron búsquedas complementarias en Google Scholar, ResearchGate y listados de referencias de los estudios seleccionados. Se incluyeron estudios in vitro en idioma inglés que compararon el impacto de los ARQMC comerciales y técnicas convencionales de remoción de caries en la RU de sistemas adhesivos a dentina de dientes humanos. Dos autores estandarizados realizaron la extracción, tabulación de los datos metodológicos y resultados de cada estudio en planillas de Microsoft Excel ${ }^{\circledR}$. Además, se realizó el análisis del riesgo de sesgo de los estudios seleccionados.

Resultados. En total, 22 estudios fueron incluidos, la mayoría presentó riesgo de sesgo medio $(n=15)$. Los ARQMC más evaluados fueron Carisolv ${ }^{\oplus}(n=16)$, Papacarie ${ }^{\oplus}(n=7)$ y Carie-Care ${ }^{\oplus}(n=2)$. No hubo disminución significativa en la RU de sistemas adhesivos con el uso previo de Carisolv ${ }^{\circledR}$ (13 de 16 estudios), Papacarie $^{\circledR}$ (5 de 7 estudios) y Carie-Care ${ }^{\circledR}$ ( 2 de 2 estudios) comparado con las técnicas convencionales de remoción de caries. No se encontró relación con el tipo de sistema adhesivo utilizado entre los estudios que mostraron impacto negativo de los ARQMC en la RU a dentina.

Conclusiones. El uso de ARQMC como Carisolv ${ }^{\circledR}$ y Papacarie ${ }^{\circledR}$ antes de la aplicación sistemas adhesivos no afecta la RU de sistemas adhesivos a dentina. El impacto del ARQMC Carie-Care ${ }^{\circledR}$ en la adhesión en dentina requiere futuras investigaciones.

\section{Resistencia de unión de sistemas adhesivos en esmalte dental fluorótico: Una revisión sistemática}

Samantha Molina Pérez', María Luisa Redondo Rico', Daniela Palacio Vivanco', Fraider Gutiérrez Meza' ${ }^{1}$ Ana Leonor Herrera Gómez ${ }^{1}$, Sthefanie Pérez Puello² , Mario Fernando de Goes³ Cristhian Camilo Madrid Troconis ${ }^{3}$

'Estudiante de pregrado. Facultad de Odontología de la Universidad de Cartagena, Cartagena de Indias, Colombia.

2Docente, Programa de odontología, Corporación Universitaria Rafael Núnez, Cartagena de Indias, Colombia

Docente de la Facultad de Odontología de Piracicaba, Universidad Estadual de Campinas (FOP-UNICAMP), Brasil

${ }^{3}$ Docente del Departamento de Rehabilitación Oral. Facultad de Odontología de la Universidad de Cartagena, Cartagena de Indias, Colombia.

Objetivo: Analizar la literatura sobre la resistencia de unión (RU) de sistemas adhesivos (SA) a esmalte fluorótico en comparación con el esmalte sano.

Métodos: La revisión sistemática se realizó siguiendo la guía PRISMA Se realizaron búsquedas sistemáticas en las bases de datos PubMed/ Medline, Scopus y EBSCOHost (última actualización el 1 de abril de 2021), utilizando las palabras clave "Dental fluorosis", "fluorotic enamel","fluorosed teeth","fluorosed enamel","bond strength","bonding", "adhesion"y"adhesive system". Los resultados de las búsquedas fueron exportados a Rayyan Systems Inc. para eliminar duplicados, lectura de resúmenes y clasificación inicial. Se incluyeron estudios en idioma inglés que compararon la RU de sistemas adhesivos a esmalte fluorótico y esmalte sano. Los principales datos metodológicos de cada estudio fueron extraídos y tabulados en Microsoft Excel ${ }^{\circledR} 2016$ por dos autores previamente estandarizados. Además, se extrajeron las medias de RU de SA y se calculó la diferencia de medias en los estudios individuales. El riesgo de sesgo de los estudios fue determinado por dos autores estandarizados, utilizando un instrumento adaptado.

Resultados: En total, 10 artículos fueron incluidos, de los cuales 8 artículos (80\%) mostraron disminución significativa en la RU de SA a esmalte fluorótico, 1 artículo (10\%) mostró efecto dependiente del grado de severidad de la fluorosis y 1 artículo (10\%) no reveló ningún efecto negativo. La mayoría de los estudios ( $\mathrm{n}=9$ ) presentó riesgo de sesgo medio. En general, el impacto negativo en la RU de los SA varió dependiendo el grado de fluorosis: leve (7,5\% a $46,66 \%)$, moderada $(7,59 \%$ a $57,15 \%)$ y severa $(3,0 \%$ a $71,42 \%)$.

Conclusiones: La RU de SA a esmalte fluorótico fue menor en comparación con esmalte sano. El grado de severidad de la fluorosis dental tiene un impacto negativo en la RU de los SA. 


\section{Estrategias para el flujo de atención odontológica en contexto de pandemia en Chile}

Consuelo Gajardoํ, Camila Ruiz' ${ }^{1}$ Cynthia Cantarutti ${ }^{1}$

'Facultad de Medicina, Escuela de odontología, Pontificia Universidad Católica de Chile

La enfermedad de COVID-19 causada por el virus SARS-CoV-2, comenzó en Wuhan, China a finales del año 2019 y desde entonces ha sido un problema de salud pública debido a su rápida propagación a escala mundial. Chile ha implementado medidas para disminuir los casos de contagio dentro del plan "Paso a Paso: Chile se recupera"; a raíz de estos cambios ha disminuido el número de atenciones odontológicas en conjunto con una reformulación del flujo de atención acorde a las nuevas normas sanitarias. La presente revisión narrativa tiene como objetivo describir el flujo de atención en salud dental durante la pandemia de COVID-19 a nivel internacional y en Chile. Descubriendo sus respectivas debilidades y fortalezas que permitan elaborar una propuesta de flujo de atención en Chile eficaz durante la pandemia y que pueda perdurar en el tiempo. Se realizó una estrategia de búsqueda en distintas bases de datos electrónicas utilizando términos claves definidos acorde al objetivo y además se revisó información gubernamental oficial 10 países además de Chile para poder hacer una comparativa adecuada. La información obtenida permitió abarcar algunos temas como: flujo de atención y prioridades en odontología, equipo de protección personal y teleodontologia.

\section{Rol de la Odontología en la resistencia antibiótica: ¿Cómo prevenirla?}

\author{
Aldana $\mathrm{M}^{1}$, Barraza $\mathrm{H}^{1}$, Carter $\mathrm{M}^{1}$, Fuentes J', Oddo J1', Tagle $\mathrm{M}^{1}$, \\ Ubilla ${ }^{1}{ }^{1}$, Mellado $\mathrm{B}^{1}$ \\ 'Escuela de Odontología, Facultad de Medicina. Pontificia Universidad \\ Católica de Chile
}

Resumen: Actualmente la resistencia antibiótica ha alcanzado niveles peligrosos. Uno de los factores contribuyentes es la sobre prescripción de estos fármacos realizado principalmente por médicos y odontólogos. El objetivo de esta revisión no sistemática consiste en identificar cómo la práctica odontológica contribuye a la resistencia antibiótica y si existen medidas efectivas para prevenirla.

Método: Para la búsqueda de artículos se utilizó el buscador PubMed MeSH, con los términos ("Dentistry"[Mesh]) AND ("Drug Resistance, Bacterial"[Mesh] AND "Anti-Bacterial Agents") obteniéndose 110 artículos. Luego se aplicó el filtro de "full text", para finalmente aplicarar los filtros "10 years" $y$ "humans" donde se obtuvieron 33 artículos. De estos se seleccionaron los artículos que se relacionaban directamente con la práctica odontológica.

Resultados: La odontología contribuye principalmente por la prescripción indiscriminada de antibióticos a pacientes que, en ocasiones, no lo necesitan. Algunas de las medidas para contribuir en la reducción de la resistencia antimicrobiana son: realizar un diagnóstico correcto, implementar una red nacional de vigilancia y actualizar las guías clínicas según estudios de susceptibilidad.

Discusión: Chile hoy tiene leyes sobre la regulación de la venta de antibióticos y ha tomado medidas educativas contra la resistencia antibiótica, pero ninguna está focalizada hacia la odontología, lo que es preocupante, ya que esta área prescribe aproximadamente el $10 \%$ de los antibióticos a nivel mundial.

Conclusión: La resistencia antibiótica es un problema de salud pública a nivel mundial. El odontólogo cumple un rol importante a la hora de contribuir a esta, pero no se puede dejar de lado el rol del paciente, respecto a no automedicarse y respetar la duración de los tratamientos. Según los datos recabados, a modo de sugerencia, una medida que podría tomar el Ministerio de Salud sería regular la cantidad de antibióticos prescritos, mediante una notificación semanal o mensual, indicando la dosis y la duración del tratamiento.

\section{Rol del Virus Epstein Barr y Virus Papiloma Humano en el desarrollo del cáncer oral: revisión bibliográfica}

Michela Migliaro', Ana María Brahm', María Fernanda Infante', María Trinidad San Martín', Daniela Massuh¹, Duniel Ortuño

'Escuela de Odontología, Facultad de Medicina, UC.

Introducción: El cáncer de cabeza y cuello (CCC) es un problema de salud pública a nivel mundial, que abarca diferentes tipos de cáncer. Entre estos, el cáncer oral (CO) representa el $2 \%$ de todos los cánceres del organismo, y es la quinceava causa de mortalidad por cáncer en el mundo. El Virus Papiloma Humano (VPH) es un virus de transmisión sexual, cuya infección es un factor etiológico de los cáncer oral y orofaríngeo. El Virus Epstein Barr (VEB) pertenece a la familia del virus herpes humano, encontrándose frecuentemente en carcinomas orales y orofaríngeos.

Objetivo: Describir la asociación y mecanismos relacionados entre VPH, VEB y desarrollo de cáncer oral y faríngeo.

Métodos: Se realizó una búsqueda utilizando las bases de datos PubMed, Google Scholar y SciELO, incluyendo artículos de máximo 
10 años, según pertinencia de título y abstract. Se seleccionaron 22 artículos para esta revisión narrativa.

Resultados: Dentro de los mecanismos carcinogénicos del VPH, las proteínas E6 y E7 son responsables del proceso de malignización, inhibiendo los supresores tumorales $\mathrm{p} 53$ y pRb. Otros mecanismos incluyen: evasión inmunitaria, facilitación de inestabilidad genómica, y cambios en la metilación y expresión del ADN del huésped.

Se ha descrito el fenómeno "Hit \& Run" en que el VEB manipula el mecanismo epigenético del hospedero, gatillando el proceso tumoral, sin que el virus siga estando presente. Así, genera una "reprogramación celular", produciendo cambios heredables en la expresión de genes, sin involucrar mutación del ADN. Otros mecanismos incluyen: proliferación celular indefinida, inhibición de la apoptosis, inestabilidad genómica y migración celular.

Conclusión: Existe asociación entre la carcinogénesis de los CCC con VPH y VEB. Se requieren estudios adicionales para esclarecer los mecanismos causales e interacción de ambos virus en el desarrollo del cáncer; y, en el caso de VEB, para obtener biomarcadores de mayor especificidad.

\section{Situación periodontal de niños, niñas y adolescentes en Chile: Una revisión} narrativa

Ottesen, Frank $^{1}(*)$, Massiel, Macarena ${ }^{1}$, Morales, Alicia $^{23}$

'Estudiante de Pregrado, Facultad de Odontología, Universidad de Chile. ${ }^{2}$ Departamento de Odontología Conservadora, Facultad de Odontología, Universidad de Chile.

${ }^{3}$ Centro de Epidemiología y Vigilancia de las Enfermedades Orales, CEVEO. Facultad de Odontología, Universidad de Chile.

Introducción: Las enfermedades periodontales (EP) son un problema de salud mundial por su elevada prevalencia. Son definidas como una condición inflamatoria crónica que afecta tejidos de soporte y protección del diente, y que pueden afectar la salud oral desde la temprana infancia.

Objetivo: Sintetizar resultados sobre estudios epidemiológicos de EP en niños, niñas y adolescentes (NNA) tanto a nivel nacional como regional, para así poder determinar su prevalencia.

Metodología: Se realizó una búsqueda narrativa en repositorios electrónicos y fuentes de referencia nacional (Ministerio de Salud) sobre prevalencia de EP en población infantil y adolescente de Chile ( $\leq 21$ años).
Resultados: Se encontraron 2 estudios de representatividad nacional y 3 regionales. A nivel nacional, en sujetos de 6 años, la prevalencia de gingivitis fue de 55,09\%, y a los 12 años, ésta aumentaba a un $67 \%$. En la región Metropolitana en adolescentes, se observó una pérdida de inserción clínica $\geq 1 \mathrm{~mm}$ en el $69,2 \%$ de ellos $\geq 3 \mathrm{~mm}$ en 4,5\%. En el Maule, del 59.8\% al 92\% de los NNA de 6, 12 y 15 años presentaron niveles moderados de placa bacteriana e inflamación gingival. En Valparaíso la presencia de gingivitis localizada en niños de 6 a 12 años varió entre 40,81\% y 81,25\% según ruralidad.

Discusión: Se observa una alta prevalencia de gingivitis, pérdida de inserción, indicadores de inflamación y mala higiene oral. Sin embargo, se hace difícil el análisis debido a la ausencia de uniformidad en la definición de caso.

Conclusión: A pesar de los programas odontológicos destinados a la salud oral en NNA en Chile, se observa una alta prevalencia de EP. Es necesario evaluar estos programas, junto con el desarrollo de estudios aplicando la nueva clasificación de enfermedades periodontales 2017 .

\section{Técnica CAD/CAM comparado con técnica convencional en pacientes con indicación de restauración indirecta unitaria posterior}

\author{
Orlando Fierro', Andrés Verdugo ${ }^{1}$, Bárbara Barrientos ${ }^{1}$ \\ 'Pontificia Universidad Católica de Chile.
}

Resumen: La confección de restauraciones indirectas ha sido tradicionalmente realizada mediante técnicas convencionales de laboratorio, las cuales involucran la realización de una serie de pasos y la necesidad de que el paciente asista a varias sesiones clínicas. En las últimas décadas ha sido incorporada la técnica CAD/CAM, la cual ha simplificado la confección de restauraciones indirectas. Debido a esto, es necesario comparar el desempeño clínico de ambas técnicas. Para esto, realizamos una búsqueda de revisiones sistemáticas en Epistemoniko. Extrajimos los datos desde las revisiones identificadas, analizamos la información de los estudios primarios, realizamos un metaanálisis y preparamos una tabla de resumen de los resultados utilizando el método GRADE. La población incluida en este estudio corresponde a adultos con dientes permanentes que necesiten una restauración indirecta unitaria posterior. Identificamos tres revisiones sistemáticas que en conjunto incluyeron ocho estudios primarios, de los cuales, cinco corresponden a ensayos aleatorizados. Concluimos que la técnica 
CAD/CAM, en comparación con la convencional, probablemente aumenta la falla de la restauración y la pérdida de retención. Por otra parte, podría disminuir levemente la pérdida de vitalidad y tener nula o poca diferencia en el riesgo de extracción dentaria, riesgo de caries secundaria y cambio de color superficial, pero la certeza de la evidencia es baja.

\section{Uso de clorhexidina gel en la prevención de alveolitis seca en extracción de terceros molares inferiores: Una revisión bibliográfica}

\author{
J. Mancilla ${ }^{1}$, D. Fonseca ${ }^{2}$ \\ 'Estudiante de Odontología, Universidad Andrés Bello, Santiago de Chile. \\ ${ }^{2}$ Cirujano Dentista, Docente Pregrado Cirugía Bucal Básica, Universidad \\ Andrés Bello, Santiago de Chile.
}

Introducción: La alveolitis seca es una de las complicaciones mediatas más comunes en las extracciones dentales.

En el mercado existen varias preparaciones farmacológicas para prevenir la alveolitis, tales como apósitos, antibacterianos, antisépticos, donde la clorhexidina es uno de los antisépticos más efectivos para reducir la carga bacteriana en la boca y uno de los más estudiados, considerando diferentes formulaciones, concentraciones y dosis El objetivo del presente trabajo, es la de analizar mediante una revisión bibliográfica la eficacia del gel bioadhesivo de clorhexidina al $0.2 \%$, en la reducción de la incidencia de alveolitis seca posterior a la extracción de terceros molares impactados.

Materiales y Métodos: Búsqueda electrónica en la base de datos de "PubMed" " "Google Scholar" del término "Dry Socket", combinado con "Chlorhexidine"AND “Dental Extraction". Los criterios de inclusión fueron revisiones sistemáticas, metaanálisis y ensayos aleatorios controlados publicados entre marzo 2012 a marzo del 2021, en idioma inglés, que analizan el uso del gel de clorhexidina post exodoncia de terceros molares inferiores

Resultados: De manera inicial se encontraron un total de 20 artículos, tras filtro de inclusión-exclusión se redujo a 16 artículos, y luego de una selección de lectura de título y resumen, se escogieron 12 artículos de interés, 3 metaanálisis, 1 revisión sistemática y 8 ensayos controlados aleatorios., los cuales pasaron a lectura de artículo completo.

Discusión: La frecuencia de alveolitis fue significativamente menor en el grupo en el que se usó gel de clorhexidina después de la extracción en comparación con el grupo de control que se utilizó un gel de placebo.
Conclusión: Pese a que diversos estudios han demostrado que el uso de clorhexidina en gel disminuye la incidencia de alveolitis seca, estos presentan sesgo en su aplicación clínica. Se sugiere realizar estudios con protocolos estandarizados, con el fin de obtener estudios de mayor impacto.

\section{Uso de probióticos como terapia de Candidiasis oral. Revisión narrativa}

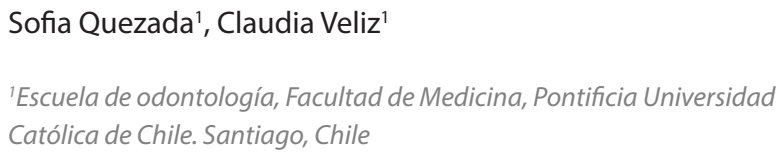

Antecedentes: La candidiasis o estomatitis oral es una enfermedad muy frecuente en la población adulta que tiene un compromiso de la inmunidad, la que se ocasiona por el crecimiento de colonias de Cándida Albicans en la cavidad bucal. El tratamiento convencional consiste en el uso de antifúngicos, sin embargo, estos han demostrado toxicidad produciendo efectos adversos en los seres humanos. Por esto han surgido terapias alternativas como los probióticos que son microrganismos vivos que confieren beneficios para la salud del huésped.

Objetivo: Realizar una revisión de la literatura sobre el uso de probióticos y su efecto en la reducción de la incidencia y prevalencia de Cándida Albicans.

Métodos: Revisión narrativa. Se utilizó el buscador PubMed con los términos MESH Probiotics y Oral Candidiases y los filtros Clinical Querries, therapy y broad. Se obtuvieron 29 artículos. Los criterios de inclusión fueron: Estudio clínico controlado aleatorizado de los últimos 8 años, Formato PDF y pacientes con factores de riesgo de candidiasis oral. Finalmente 6 estudios fueron incluidos en esta revisión.

Resultados: En 4 estudios se observa que los probióticos disminuyen la incidencia y severidad de la cándida albicans al ser consumidos en períodos prolongados ( 1 mes al menos) y en múltiples dosis ( 3 diarias). Por su parte, 2 estudios señalan que los niveles de dolor oral e incomodidad no obtuvieron resultados diferentes en comparación a la terapia convencional.

Conclusiones: El consumo habitual de probióticos reduce la incidencia y severidad de candidiasis oral. Por lo tanto, la principal ventaja de los probióticos en pacientes inmunocomprometidos es una mejora de la calidad de vida, dado que reduce los casos de candidiasis y los pacientes que cursen el cuadro presentan una menor sintomatología. Sin embargo, como terapia alternativa a la convencional, esta no generó mejores resultados. 


\section{Uso de profilaxis antibiótica en implantología: lo que la evidencia respalda}

Zumelzu Verónica', Flández Valentina' ${ }^{1}$ Claudia Crisosto²

'Universidad San Sebastián, Facultad de Odontología, Estudiante de Pregrado $5^{\circ}$ año.

${ }^{2}$ Cirujano Dentista, Especialista en Periodoncia y Rehabilitación Oral, Docente Universidad San Sebastián.

Introducción: La implantología es una opción terapéutica ampliamente utilizada. Una posibilidad de fracaso es la contaminación bacteriana en el lugar de inserción, pues la cavidad oral está expuesta a bacteriemia transitoria tras alteración de la superficie gingival, con riesgo de infección entre $10-15 \%$, reduciéndose a $1 \%$ con antibióticos profilácticos, previniendo infecciones en el sitio por la alta concentración alcanzada en sangre.

Objetivos: Analizar la recomendación de profilaxis antibiótica en cirugía de implantes dentales.

Materiales y métodos: Se realizó búsqueda sistemática en base de datos Pubmed/Medline, entre años 2015-2020, usando términos MeSH "Antibiotic Prophylaxis" "Dental Implants"; boleanos "Dentistry AND Antibiotic Prophylaxis", "Antibiotic Prophylaxis AND Dental Implants", empleando filtros: texto completo, revisión sistemática, meta-análisis, estudios aleatorios controlados.
Resultados: Se encontraron 75 artículos, seleccionando 15 por criterios de búsqueda. La profilaxis antibiótica administrada antes o después de la cirugía previene fracasos tempranos de implantes en pacientes de alto riesgo. Sin embargo, la Asociación Europea de Osteointegración no justifica su uso en pacientes sanos, ya que no se ha demostrado efecto beneficioso.

Discusión: La evidencia respalda la profilaxis antibiótica en pacientes con riesgo de endocarditis y respuesta inmune comprometida, pero no es concluyente en indicación postoperatoria. Se reporta que el uso indiscriminado de antibióticos es un factor etiológico de resistencia antibiótica. Se necesita mayor investigación para determinar la necesidad y dosis de profilaxis antibiótica durante estos procedimientos dentales. Park et al concluye que no se debe prescribir profilaxis antibiótica en pacientes sanos, mientras que Dent et al y Laskin et al, informan que los antibióticos disminuyen los fracasos de implantes dentales.

Conclusión: La evaluación del riesgo de infección en implantología debe ser individualizada, considerando factores del paciente, características de la cirugía y experiencia del clínico, entre otros. La indicación de antibióticos debe ser prudente, acorde a la evidencia disponible, la cual es controvertida y limitada. 